\title{
CFC-11, CFC-12 and HCFC-22 ground-based remote sensing FTIR measurements at Réunion Island and comparisons with MIPAS/ENVISAT data
}

\author{
Minqiang Zhou ${ }^{1,2,3}$, Corinne Vigouroux ${ }^{2}$, Bavo Langerock ${ }^{2}$, Pucai Wang ${ }^{1}$, Geoff Dutton ${ }^{4}$, Christian Hermans ${ }^{2}$, \\ Nicolas Kumps $^{2}$, Jean-Marc Metzger ${ }^{5}$, Geoff Toon ${ }^{6}$, and Martine De Mazière ${ }^{2}$ \\ ${ }^{1}$ Key Laboratory of Middle Atmosphere and Global Environment Observation, Institute of Atmospheric Physics, \\ Chinese Academy of Sciences, Beijing, China \\ ${ }^{2}$ Royal Belgian Institute for Space Aeronomy, Brussels, Belgium \\ ${ }^{3}$ University of Chinese Academy of Sciences, Beijing, China \\ ${ }^{4}$ Earth System Research Laboratory, NOAA, Boulder, Colorado, USA \\ ${ }^{5}$ UMS 3365 - OSU Réunion, Université de La Réunion, Saint-Denis, Réunion, France \\ ${ }^{6}$ Jet Propulsion Laboratory, California Institute of Technology, Pasadena, CA 91109, USA \\ Correspondence to: Minqiang Zhou (minqiang.zhou@aeronomie.be)
}

Received: 14 July 2016 - Published in Atmos. Meas. Tech. Discuss.: 21 July 2016

Revised: 18 October 2016 - Accepted: 7 November 2016 - Published: 25 November 2016

\begin{abstract}
Profiles of CFC-11 ( $\left.\mathrm{CCl}_{3} \mathrm{~F}\right), \mathrm{CFC}-12\left(\mathrm{CCl}_{2} \mathrm{~F}_{2}\right)$ and $\mathrm{HCFC}-22\left(\mathrm{CHF}_{2} \mathrm{Cl}\right)$ have been obtained from Fourier transform infrared (FTIR) solar absorption measurements above the Saint-Denis (St Denis) and Maïdo sites at Réunion Island $\left(21^{\circ} \mathrm{S}, 55^{\circ} \mathrm{E}\right)$ with low vertical resolution. FTIR profile retrievals are performed by the well-established SFIT4 program and the detail retrieval strategies along with the systematic/random uncertainties of CFC-11, CFC-12 and HCFC-22 are discussed in this study. The FTIR data of all three species are sensitive to the whole troposphere and the lowermost stratosphere, with the peak sensitivity between 5 and $10 \mathrm{~km}$.

The ground-based FTIR data have been compared with the collocated Michelson Interferometer for Passive Atmospheric Sounding (MIPAS/ENVISAT) data and found to be in good agreement: the observed mean relative biases and standard deviations of the differences between the smoothed MIPAS and FTIR partial columns $(6-30 \mathrm{~km})$ are $(-4.3$ and $4.4 \%),(-2.9$ and $4.6 \%)$ and (-0.7 and $4.8 \%)$ for CFC- 11 , CFC-12 and HCFC-22, respectively, which are within the combined error budgets from both measurements. The season cycles of CFC-11, CFC-12 and HCFC-22 from FTIR measurements and MIPAS data show a similar variation: concentration is highest in February-April and lowest in August-October.
\end{abstract}

The trends derived from the combined St Denis and Maïdo FTIR time series are $-0.86 \pm 0.12$ and $2.84 \pm 0.06 \%$ year $^{-1}$ for CFC-11 and HCFC-22, respectively, for the period 2004 to 2016 , and $-0.76 \pm 0.05 \%$ year $^{-1}$ for CFC-12 for 2009 to 2016. These measurements are consistent with the trends observed by the National Oceanic and Atmospheric Administration (NOAA) Global Monitoring Division's (GMD) Halocarbons \& other Atmospheric Trace Species Group (HATS) measurements at Samoa $\left(14.2^{\circ} \mathrm{S}, 170.5^{\circ} \mathrm{W}\right)$ for CFC-11 $\left(-0.87 \pm 0.04 \%\right.$ year $\left.^{-1}\right)$, but slightly weaker for HCFC-22 $(3.46 \pm 0.05 \%)$ year $^{-1}$ and stronger for CFC-12 $\left(-0.60 \pm 0.02 \%\right.$ year $\left.^{-1}\right)$.

\section{Introduction}

CFC-11 $\left(\mathrm{CCl}_{3} \mathrm{~F}\right), \quad \mathrm{CFC}-12 \quad\left(\mathrm{CCl}_{2} \mathrm{~F}_{2}\right)$ and HCFC-22 $\left(\mathrm{CHF}_{2} \mathrm{Cl}\right)$ are the major sources of chlorine in the stratosphere after photolytic decomposition and therefore play an important role in stratospheric ozone depletion (Molina and Rowland, 1974). In addition, these gases absorb thermal infrared radiation and contribute significantly to the greenhouse effect (Lashof and Ahuja, 1990). Due to the long lifetime of these gases (CFC-11: 60 years; CFC-12: 
$\sim 120$ years; HCFC-22: 12 years; Ko et al., 2013), they are good tracers to study transport and mixing processes in the upper troposphere and lower stratosphere region (Hoffmann and Riese, 2004).

Because of the vital importance of these gases, the Advanced Global Atmospheric Gases Experiment (AGAGE) in situ network has been measuring CFC-11 and CFC-12 continuously since 1978 and HCFC-22 since the 1990s (Cunnold et al., 1997; Dunse et al., 2005). NOAA's Halocarbons \& other Atmospheric Trace Species Group (HATS) sampling network started monitoring chlorofluorocarbon (CFCs) from flask grab samples in 1977 and via online in situ techniques starting in 1977 (Elkins et al., 1993). HCFC-22 was added to the NOAA/HATS measurements in 1992. Because of the use of CFCs as propellant and refrigerant in the 1980s, the in situ measurements show the rapid rise of CFC-11 and CFC12 at that time. To reduce substances that deplete the ozone layer, amongst others CFCs, 27 nations around the world signed a global environmental treaty, the Montreal Protocol, in September 1987 (Murdoch and Sandler, 1997). The hydrochlorofluorocarbons (HCFCs) were applied to replace the CFCs after the Montreal Protocol, since they react with tropospheric hydroxyl $(\mathrm{OH})$, resulting in a shorter lifetime compared with CFCs. As a result, accelerated increases are observed for HCFCs since 2004 in the global atmosphere (Montzka et al., 2009). The tropospheric concentrations of CFC-11 and CFC-12 reached their maximums in 1992 and 2003, respectively, and a decline has been observed since then (Elkins et al., 1993; Montzka et al., 1996; Walker et al., 2000).

Apart from the in situ measurements, observations of CFCs and HCFCs abundances have also been made using remote sensing infrared spectroscopy techniques. Space-based observations provide the global distributions and trends of CFCs and HCFCs; examples are the measurements of CFC-11 and CFC-12 from ILAS (Improved Limb Atmospheric Spectrometer), CFC-11, CFC-12, CFC-113, HCFC22, HCFC-142a and HCFC-142b from ACE-FTS (Atmospheric Chemistry Experiment Fourier transform spectrometer) and CFC-11, CFC-12 and HCFC-22 from MIPAS (Michelson Interferometer for Passive Atmospheric Sounding) (Khosrawi et al., 2004; Hoffmann et al., 2008; Mahieu et al., 2008). Also ground-based FTIR measurements are able to monitor the CFCs and HCFCs (Notholt, 1994), especially at the Swiss Jungfraujoch station (Zander et al., 2005; Mahieu et al., 2010, 2013), where comparisons with the ACE-FTS measurements show a good agreement (Mahieu et al., 2015). Trend studies of HCFC-22 from FTIR measurements have been conducted both in the Northern Hemisphere (Zander et al., 1994) and in the Southern Hemisphere at the Lauder station (Sherlock et al., 1997), for the period from the mid-1980s to the mid-1990s. FTIR can provide long time series of CFC-11, CFC-12 and HCFC-22 total columns and are therefore very good candidates for supporting the evaluation of satellite and model data and for the evaluation of trends: the Jungfraujoch CFC-11, CFC-12 and HCFC-22 time series and trends have been included in the most recent Scientific Assessment of Ozone Depletion (Carpenter et al., 2014).

In this study, we provide the first ground-based FTIR time series of CFC-11, CFC-12 and HCFC-22 in the Southern Tropics, namely at two stations located at Réunion Island $\left(21^{\circ} \mathrm{S}, 55^{\circ} \mathrm{E}\right)$, Saint-Denis (St Denis) and Maïdo, and we compare them to MIPAS/ENVISAT collocated data. Section 2 describes the FTIR experiments at Réunion Island as well as the retrieval strategy for each specie along with the uncertainty analysis. Section 2 also shows the time series of the FTIR measurements and American Samoa (SMO) in situ measurements for CFC-11 and CFC-12 and flask samplings for HCFC-22, which is one of NOAA's baseline observatories $\left(14.2^{\circ} \mathrm{S}, 170.5^{\circ} \mathrm{W} ; 77 \mathrm{~m}\right.$ a.s.l. $)$ at a similar latitude as Réunion Island. Vertical profile and partial column comparisons of the FTIR measurements with the MIPAS data are discussed in Sect. 3. Additionally, we provide the three species' trends derived from our FTIR time series and compare them to the trends observed by MIPAS data and SMO data. Finally, conclusions are drawn in Sect. 4.

\section{Réunion Island FTIR data}

\subsection{FTIR experiments at Réunion Island}

As explained in Baray et al. (2013), the atmospheric observations at Réunion Island are carried out at two sites, namely St Denis $\left(20.90^{\circ} \mathrm{S}, 55.48^{\circ} \mathrm{E} ; 85 \mathrm{~m}\right.$ a.s.l.), close to the coast, and the Maïdo mountain site $\left(21.07^{\circ} \mathrm{S}, 55.38^{\circ} \mathrm{E}\right.$; $2155 \mathrm{~m}$ a.s.l.). At present, both sites are equipped with a Bruker 125HR FTIR instrument. These FTIR instruments contribute to two important networks: NDACC (Network for the Detection of Atmospheric Composition Change) committed to monitoring the atmospheric gas and understanding their impact on climate change and TCCON (Total Carbon Column Observing Network) dedicated to greenhouse gas observations. Each network requires a particular spectral coverage (mid-infrared $\left(600-4500 \mathrm{~cm}^{-1}\right)$ in NDACC and near-infrared (4000-8000 $\left.\mathrm{cm}^{-1}\right)$ in TCCON) and therefore a corresponding instrumental configuration (optical filters, beam splitters and detectors) and operation mode (including spectral resolution). Since March 2013, when the FTIR spectrometer at Maïdo became operational, the Maïdo FTIR has been dedicated to NDACC and the St Denis FTIR to TCCON.

\subsubsection{La Réunion - St Denis}

The Royal Belgian Institute for Space Aeronomy (BIRAIASB) started the FTIR solar absorption experiments at La Réunion in St Denis in 2002, with a Bruker 120M FTIR spectrometer, first on a campaign basis with campaigns in 2002 (October), 2004 (August to October) and 2007 (May to November), and then in continuous mode since June 2009 
Table 1. Microwindows, interfering gases, spectroscopic database, a priori profile and background parameters (slope, curvature, zshift and beam as discussed in Sect. 2.2.1) used for the SFIT4 retrievals of CFC-11, CFC-12 and HCFC-22. The degree of freedom for signal (DOFS, mean and standard deviation) of retrievals at St Denis and Maïdo.

\begin{tabular}{llll}
\hline Target gas & $\mathrm{CFC}-11\left(\mathrm{CCl}_{3} \mathrm{~F}\right)$ & $\mathrm{CFC}-12\left(\mathrm{CCl}_{2} \mathrm{~F}_{2}\right)$ & HCFC-22 $\left(\mathrm{CHF}_{2} \mathrm{Cl}\right)$ \\
\hline Microwindows $\left(\mathrm{cm}^{-1}\right)$ & $830.0-860.0$ & $1160.2-1161.4$ & $828.6-831.0$ \\
Profile retrieval & $\mathrm{CFC}-11, \mathrm{H}_{2} \mathrm{O}$ & $\mathrm{CFC}-12, \mathrm{~N}_{2} \mathrm{O}$ & $\mathrm{HCFC}-22$ \\
Column retrieval & $\mathrm{HNO}_{3}, \mathrm{O}_{3}, \mathrm{COCl}_{2}, \mathrm{CO}_{2}$ & $\mathrm{O}_{3}, \mathrm{CH}_{4}, \mathrm{H}_{2} \mathrm{O}$ & $\mathrm{CO}_{2}, \mathrm{H}_{2} \mathrm{O}, \mathrm{O}_{3}$ \\
Spectroscopy & PLL, $\mathrm{HITRAN2012}$ & PLL, $\mathrm{HITRAN2012}$ & $\mathrm{PLL}_{2} \mathrm{HITRAN} 2012$ \\
A priori profile & WACCM & WACCM & WACCM \\
St Denis background & slope, curvature, zshift & slope & slope \\
Maïdo background & slope, curvature, zshift, beam & slope & slope \\
DOFS (St Denis) & $1.1 \pm 0.1$ & $1.5 \pm 0.1$ & $0.9 \pm 0.1$ \\
DOFS (Maïdo) & $1.0 \pm 0.1$ & $1.5 \pm 0.1$ & $1.1 \pm 0.1$ \\
\hline
\end{tabular}

(Senten et al., 2008; Vigouroux et al., 2009, 2012; Duflot et al., 2010; Baray et al., 2013). In September 2011, BIRAIASB started the replacement of the Bruker $120 \mathrm{M}$ by a Bruker 125HR: the Bruker 125HR was installed next to the Bruker $120 \mathrm{M}$ and both instruments were set up to make collocated measurements until November 2011, when BIRAIASB disassembled the Bruker 120M. Since then, at St Denis, BIRA-IASB operates only the Bruker 125HR, and this instrument is primarily dedicated to TCCON measurements Therefore, the KBr beam splitter and the MCT detector (600$1400 \mathrm{~cm}^{-1}$ ), required for the retrievals of the three species presented in this work, were not installed in the new Bruker $125 \mathrm{HR}$ configuration at St Denis. As a consequence, the time series of the three species at St Denis cover only the August 2004-November 2011 period.

\subsubsection{La Réunion - Maïdo}

BIRA-IASB started operating a second Bruker 125HR FTIR spectrometer at the Maïdo observatory in March 2013 and dedicated it primarily to NDACC measurements with MCT and InSb detectors. As such, our CFCs and HCFC time series at Maïdo cover the March 2013-present time period.

\subsection{FTIR retrieval}

The NDACC ground-based FTIR experiment observes the absorption of the direct solar radiation with high spectral resolution $\left(0.0035-0.0110 \mathrm{~cm}^{-1}\right)$ and uses the pressure broadening effect of absorption lines to retrieve volume mixing ratio (vmr) profiles of target gases. In this study, the FTIR retrievals are based on an optimal estimation method (Rodgers, 2000), carried out with the SFIT4 algorithm (https: //wiki.ucar.edu/display/sfit4), which is an open source code, largely developed by lead contributors from the University of Bremen and National Center for Atmospheric Research (NCAR) with other contributions from several other institutions within NDACC. The National Centers for Environmental Prediction (NCEP) provide the 6-hourly pressure and tem- perature profiles. The difference between NCEP and the balloon sounding measurements above Réunion Island is used to create the systematic and random error covariance matrices of the water vapor and temperature profiles. $\mathrm{HBr}$ cell measurements performed on a daily basis to verify the alignment of the instrument and to obtain the instrument line shape (ILS) using the LINEFIT14.5 program (Hase et al., 1999); the ILS is provided as an input parameter in the forward model of SFIT4.

\subsubsection{Retrieval strategy}

CFC-11, CFC-12 and HCFC-22 have weak absorptions in the infrared spectral range, requiring careful selection of the retrieval spectral windows in order to minimize the interfering absorptions from other species. The microwindows (see Table 1) for CFC-11 are the same as in the work of Mahieu et al. (2010). For CFC-12, the $922.50-923.60 \mathrm{~cm}^{-1}$ window is, however, not appropriate for the humid site of Réunion Island because of the strong water vapor lines present at the edge of the window $\left(922.13 \mathrm{~cm}^{-1}\right)$. To avoid such interferences from water vapor, we prefer to use the $1160.2-1161.4 \mathrm{~cm}^{-1}$ for our CFC-12 retrievals at Réunion Island. For HCFC-22, a larger microwindow $\left(828.6-831.0 \mathrm{~cm}^{-1}\right)$ is adopted in this study, compared with $828.75-829.4 \mathrm{~cm}^{-1}$ (Mahieu et al., 2010). Such a large microwindow allows us to obtain a better fit of the background, which is determined by water vapor and other parameters. The left panels in Fig. 1 show the typical transmittances along with the absorption lines of the target and interfering species, as well as the fitting residuals for the CFC-11, CFC-12 and HCFC-22 retrievals at St Denis. The interfering gases are also listed in Table 1: as indicated in the table, either a full profile retrieval is performed or only a scaling of the a priori profile (column retrieval).

In each microwindow, the background transmittance $\boldsymbol{\beta}$ describes the shape caused by the optics in the instrument (especially the bandpass filter) as a second-order polynomial of 

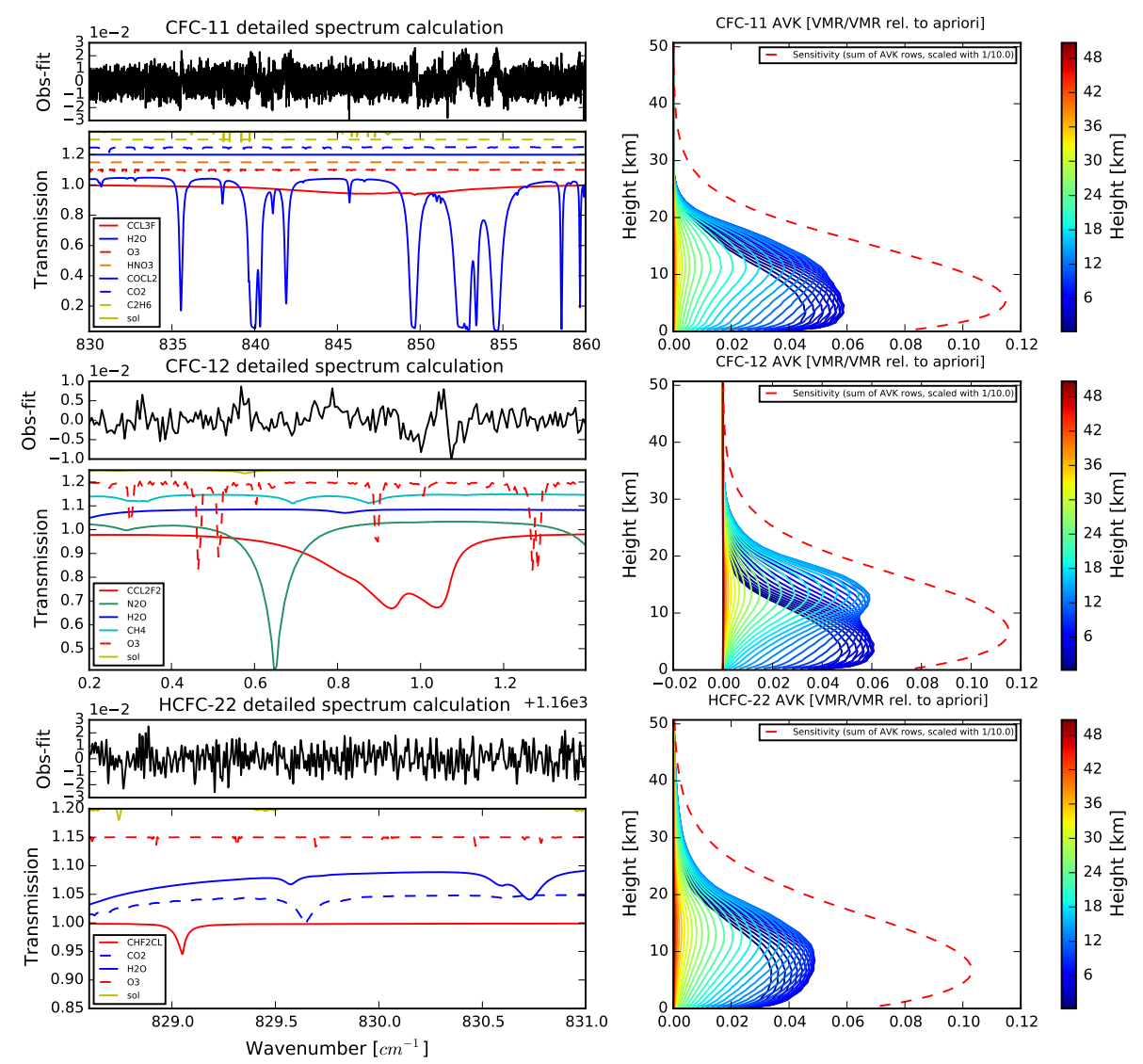

Figure 1. The typical spectrum and averaging kernels of CFC-11 (upper), CFC-12 (middle) and HCFC-22 (bottom) at St Denis. The left panels show the transmission and residual (observed - calculated spectrum) for the three retrieval microwindows, along with the absorption contribution from each specie. To clarify the absorption lines, the transmittance is shifted by 0.05 for each specie and solar line. Right panels show the averaging kernels for the target gases (no sensitivity above $50 \mathrm{~km}$ ). The solid lines represent the sensitivities at specific altitudes. The red dashed line is the sum of the row of averaging kernel scaled by 0.1 , indicating the vertical sensitivity.

the wavenumber:

$\boldsymbol{\beta}=\frac{\left[1+a\left(\boldsymbol{w}-w_{0}\right)+b\left(\boldsymbol{w}-w_{0}\right)^{2}\right]}{\left(1+z_{0}\right)}$.

In Eq. (1), $a$ is the slope coefficient, $b$ is the curvature coefficient, $w_{0}$ is the first wavenumber in the microwindow $\left(\mathrm{cm}^{-1}\right), \boldsymbol{w}$ is the vector of all wavenumber in the microwindow and $z_{0}$ is the zero level offset (zshift). The parameters $a$, $b$ and $z_{0}$ can be fitted in SFIT4 in addition to the target gases profiles and interfering species profiles or columns. The calculated transmittance $\boldsymbol{y}_{\mathrm{c}}$ is the result of bringing the background, absorptions and zshift together:

$\boldsymbol{y}_{\mathrm{c}}=\boldsymbol{\beta} \cdot\left(\boldsymbol{\zeta}(\boldsymbol{t}(\boldsymbol{w}))+z_{0}\right)$,

where $\boldsymbol{t}(\boldsymbol{w})$ is the calculated transmittance (after the absorption from each species and solar lines) and $\zeta(t(w))$ is the transmittance after convolution with the ILS.

Some low-frequency oscillations of the baseline can occur in the spectra, resulting from the mirrors, filters or apertures. While this is not a problem for small retrieval win- dows (a slope and a curvature are sufficient to fit the baseline), it could be necessary in the case of wide window to include a so-called "beam correction" to fit these oscillations. In SFIT4, this is done by adding a zshift-like parameter $z_{b}$ for the interferogram perturbation (IP) model:

$\boldsymbol{y}_{\mathrm{c}}=\boldsymbol{\beta} \cdot\left(\boldsymbol{\zeta}(\boldsymbol{t}(\boldsymbol{w}))+z_{0}+z_{b}\right)$.

SFIT4 uses four parameters ( $A$ is amplitude, $T$ is period, $\psi$ is phase and $\tau$ is slope for the amplitude) to retrieve each beam (the number of beams could be more than one):

$$
\begin{aligned}
& \vartheta=A\left(1+\tau\left(\boldsymbol{w}-w_{0}\right)\right) e^{i(2 \pi / T(\boldsymbol{w}-\psi))}, \\
& z_{b}=\boldsymbol{\zeta}(\vartheta) .
\end{aligned}
$$

Table 1 lists the parameters used for fitting the background in the CFC-11, CFC-12 and HCFC-22 retrievals. Since the retrieval windows of CFC-12 and HCFC-22 are narrow, a linear fit is enough to characterize the spectral background $(b=0)$. However, the retrieval window of CFC-11 (830$860 \mathrm{~cm}^{-1}$ ) is very wide and contains several saturated $\mathrm{H}_{2} \mathrm{O}$ 


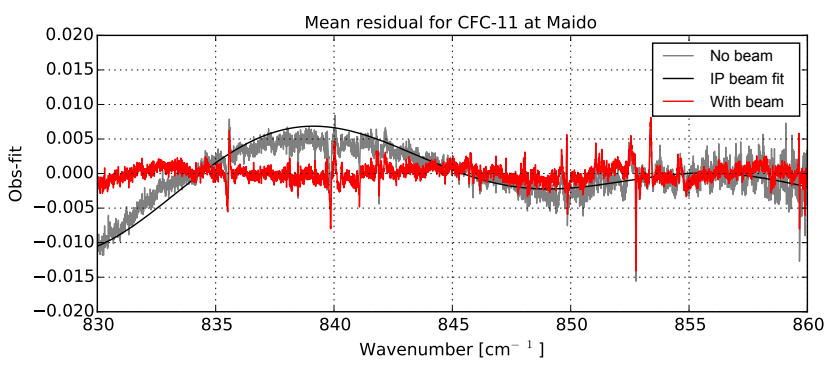

Figure 2. The mean residual transmittance (observed-calculated) of the CFC-11 retrievals with and without beam parameters at Maïdo. The IP beam fit line is used as a priori IP beam parameters.

absorption lines; therefore zshift, slope and curvature were retrieved together to fit the oscillating shape of the background in the CFC-11 microwindow. For the CFC-11 retrieval at Maïdo, it turned out to be necessary to retrieve one IP-type beam as well (Eqs. 3-5). Together with one IP-type beam, the retrieved CFC-11 total columns at Maïdo show better agreements with MIPAS data and the ground-based HATS SMO in situ measurements along with a much smaller fitting residual in comparison with without-beam retrievals. Figure 2 shows the average residual transmittance for the CFC-11 retrievals at Maïdo, with and without fitting a beam parameter. The spikes mainly result from the strong absorption lines of $\mathrm{H}_{2} \mathrm{O}$. The a priori values for the IP beam parameters were obtained by fitting the mean residuals of all without-beam retrievals. It is clear from Fig. 2 that adding one IP-type beam was useful to remove the background oscillation of the residuals at Maïdo. As such an oscillation was not found for the St Denis CFC-11 residuals, the beam parameters retrieval was only applied for Maïdo.

We use the empirical pseudo-line-lists (PLL) created by G. Toon (details see http://mark4sun.jpl.nasa.gov/pseudo. html) for the CFC-11, CFC-12, HCFC-22 and $\mathrm{COCl}_{2}$ spectroscopy, and HITRAN 2012 (Rothman et al., 2013) for the remaining species (see Table 1).

The a priori profiles of interfering gases, except $\mathrm{H}_{2} \mathrm{O}$ and $\mathrm{O}_{3}$, are the mean of 1980-2020 monthly data from Whole Atmosphere Community Climate Model (WACCM, version 6, ftp://acd.ucar.edu/user/jamesw/IRWG/ 2013/WACCM/V6/). In order to reduce the influence of $\mathrm{O}_{3}$ and $\mathrm{H}_{2} \mathrm{O}$ uncertainties, preliminarily retrieved profiles of $\mathrm{O}_{3}$ and $\mathrm{H}_{2} \mathrm{O}$ obtained with the settings of Vigouroux et al. (2015) are used as input for the CFC-11, CFC-12 and HCFC-22 retrievals. The a priori profiles of target species are the mean of 2004-2016 monthly data from WACCM after scaling to the annual mean of ground-based NOAA/HATS SMO flask grab samples and in situ measurements of 2009 for St Denis and 2014 for Maïdo. As such, the a priori profiles of CFC-11 and CFC-12 for St Denis are a little larger than the ones for Maïdo, while the a priori profile of HCFC-22 for St Denis is a little smaller than that for Maïdo (see Fig. 3). However, all the retrievals at St Denis or at Maïdo use the same a priori profiles and there is one respective a priori profile for each specific gas and site. The profiles of the three gases decrease rapidly above $20 \mathrm{~km}$ and become close to zero vmr values at $30 \mathrm{~km}$ for CFC-11, $40 \mathrm{~km}$ for CFC-12 and $100 \mathrm{~km}$ for HCFC22.

The a priori covariance matrix (regularization matrix) is another important input parameter in the optimal estimation method. Ideally, the diagonal values of the covariance matrix represent the natural variability of the gas concentration around the a priori profile. In our study, 2004-2016 monthly data from WACCM is used to provide the variability for the FTIR retrieval, which is the same data set used for creating the a priori profiles. The variabilities of CFC-11, CFC-12 and HCFC-22 are then 5, 2 and $15 \%$, respectively. The gas profile correlation width is set to $4 \mathrm{~km}$ from 0 to $100 \mathrm{~km}$ in the SFIT4 retrieval, and the retrieved profiles for CFC-11, CFC12 and HCFC-22 are shown in Fig. 3. The retrieved HCFC22 vertical profiles at St Denis show a stronger variability in the troposphere/lower stratosphere than at Maïdo. One reason is that St Denis data cover a much wider time range (8 years) than Maïdo (4 years), so that part of the variability simply comes from the trend in HCFC-22 amounts. Figure 3 shows the retrieved profiles with different color for each year, indicating that part of the variability comes from the trend. However the variability within 1 year is still stronger at St Denis compared to Maïdo: this cannot come from larger natural variability since this species is well mixed in the whole troposphere. The larger scatter at St Denis within 1 year comes from the larger random error budget at this station (see Tables 2 and 3) due to lower signal to noise ratio $(S / N)$ (larger measurement error).

Table 1 lists the degree of freedom for signal (DOFS) of the total columns of CFC-11, CFC-12 and HCFC-22, along with the standard deviation $(1 \sigma)$; they are $1.1 \pm 0.1,1.5 \pm 0.1$ and $0.9 \pm 0.1$, respectively, at St Denis and $1.1 \pm 0.1$, $1.5 \pm 0.1$ and $1.1 \pm 0.1$, respectively, at Maïdo. There is no trend in the time series of DOFS for three species at both St Denis and Maïdo, which allows us to do the seasonal cycle and trend analysis in Sect. 3. The right panels of Fig. 1 shows the typical averaging kernels (AKs) of the CFC-11, CFC-12 and HCFC-22 retrievals at St Denis; they represent the vertical sensitivity of the measurement as a function of altitude. The FTIR retrievals of all three species are sensitive to the whole troposphere and the lowermost stratosphere, with the peak sensitivity around $5-10 \mathrm{~km}$. We have to keep in mind that the retrieved profiles of CFC-11, CFC-12 and HCFC-22 have very poor vertical resolution: the DOFS range from 0.9 to 1.6 and the full widths at half maximum of the AKs are very wide $(\sim 8 \mathrm{~km})$. 

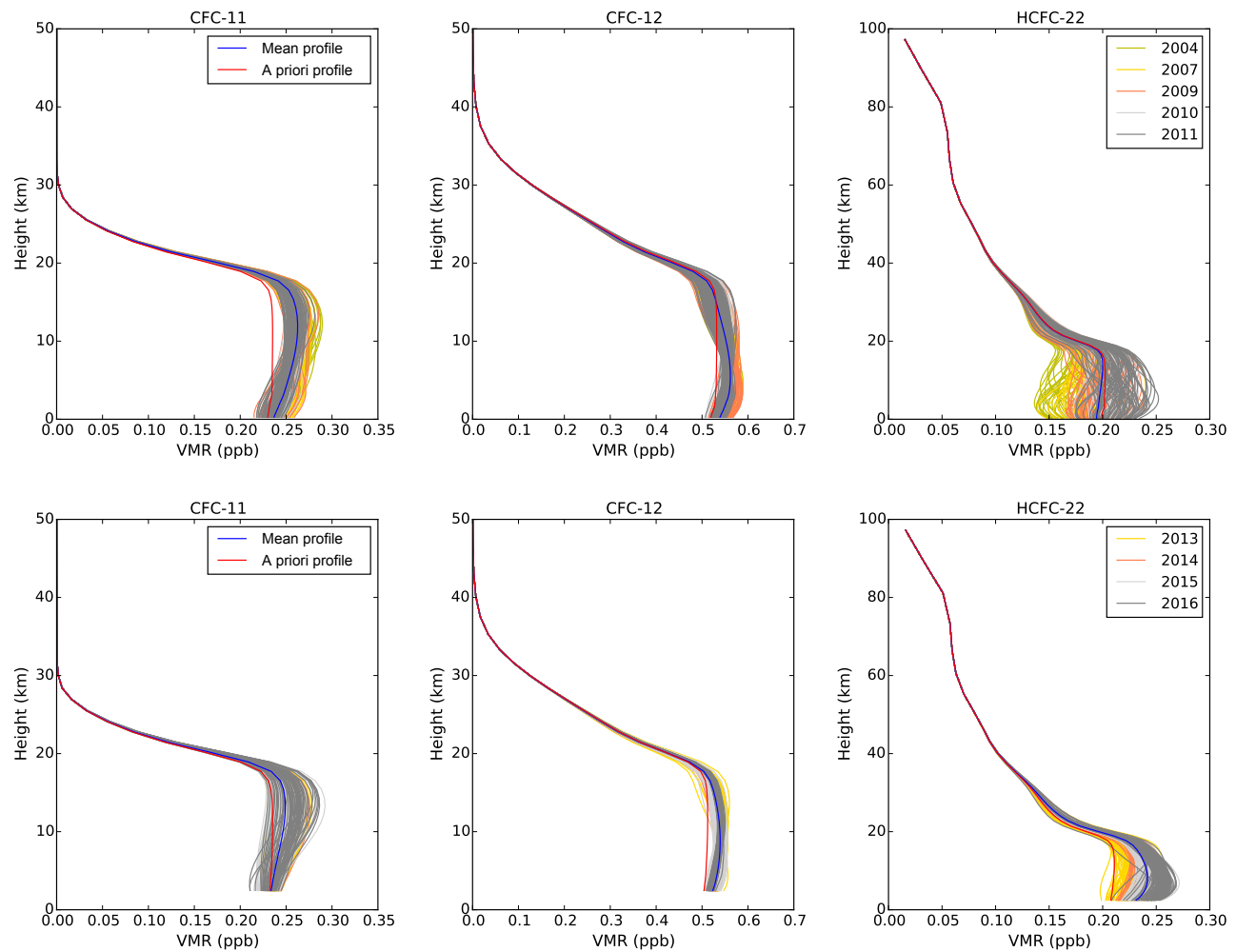

Figure 3. The a priori (red line), retrieved profiles (each year with a different color) and the mean retrieved profile (blue line) of CFC-11, CFC-12 and HCFC-22 at St Denis (upper panels) and Maïdo (bottom panels).

Table 2. Systematic and random uncertainties (in \%) for CFC-11, CFC-12 and HCFC-22 at St Denis. Sb represents the relative uncertainties (absolute value) of the non-retrieved parameters (also in \%), and the detail information about the sb value of each parameter is described in the text. For SZA, ILS and zshift, both the systematic uncertainty and the random uncertainty (in the bracket) are listed here. When a relative uncertainty is smaller than $0.01 \%$, it is considered negligible and represented as "-".

\begin{tabular}{|c|c|c|c|c|c|c|c|}
\hline \multirow[b]{2}{*}{ Error } & \multirow[b]{2}{*}{$\mathrm{Sb}$} & \multicolumn{2}{|c|}{ CFC-11 } & \multicolumn{2}{|c|}{ CFC-12 } & \multicolumn{2}{|c|}{ HCFC-22 } \\
\hline & & Systematic & Random & Systematic & Random & Systematic & Random \\
\hline Smoothing & & 0.18 & 1.03 & 0.18 & 0.79 & 0.56 & 0.60 \\
\hline Measurement & & - & 0.80 & - & 0.21 & - & 4.01 \\
\hline Retrieval parameters & & - & - & - & - & 0.20 & 0.39 \\
\hline Interfering species & & 0.12 & 0.84 & - & 0.10 & 0.29 & 1.74 \\
\hline Temperature & & 1.35 & 0.30 & 0.87 & 0.15 & 1.01 & 0.15 \\
\hline SZA & $0.1(0.2)$ & 0.21 & 0.42 & 0.36 & 0.72 & 0.58 & 1.16 \\
\hline Target line intensity & $7 / 1 / 5$ & 6.59 & - & 1.00 & - & 3.81 & - \\
\hline Target temperature dependence of line width & $7 / 1 / 5$ & - & - & - & - & 0.14 & - \\
\hline Target air-broadening of line width & $7 / 1 / 5$ & 0.45 & - & 0.07 & - & 1.36 & - \\
\hline $\mathrm{H}_{2} \mathrm{O}$ spectroscopy & 10 & 1.4 & - & 0.03 & - & 0.34 & - \\
\hline ILS & $5(5)$ & 0.02 & 0.02 & 0.04 & 0.04 & 0.26 & 0.26 \\
\hline zshift & $1(1)$ & - & - & 0.12 & 0.09 & 0.10 & 0.12 \\
\hline Total & & 7.0 & 2.0 & 1.8 & 1.1 & 4.7 & 4.4 \\
\hline
\end{tabular}


Table 3. Same as Table 2, but for Maïdo.

\begin{tabular}{|c|c|c|c|c|c|c|c|}
\hline \multirow[b]{2}{*}{ Error } & \multirow[b]{2}{*}{$\mathrm{Sb}$} & \multicolumn{2}{|c|}{ CFC-11 } & \multicolumn{2}{|c|}{ CFC-12 } & \multicolumn{2}{|c|}{ HCFC-22 } \\
\hline & & Systematic & Random & Systematic & Random & Systematic & Random \\
\hline Smoothing & & 0.23 & 0.90 & 0.02 & 0.67 & 0.38 & 0.57 \\
\hline Measurement & & - & 0.70 & - & 0.20 & - & 3.37 \\
\hline Retrieval parameters & & - & 0.26 & - & - & - & 0.10 \\
\hline Interfering species & & 0.08 & 0.20 & - & - & 0.02 & 0.02 \\
\hline Temperature & & 1.82 & 0.76 & 1.02 & 0.19 & 0.78 & 0.26 \\
\hline SZA & $0.1(0.2)$ & 0.25 & 0.51 & 0.22 & 0.44 & 0.21 & 0.42 \\
\hline Target line intensity & $7 / 1 / 5$ & 6.22 & - & 0.98 & - & 4.15 & - \\
\hline Target temperature dependence of line width & $7 / 1 / 5$ & 0.05 & - & - & - & 0.05 & - \\
\hline Target air-broadening of line width & $7 / 1 / 5$ & 1.54 & - & 0.05 & - & 1.39 & - \\
\hline $\mathrm{H}_{2} \mathrm{O}$ spectroscopy & 10 & 0.78 & - & - & - & 0.01 & - \\
\hline ILS & $5(5)$ & 0.02 & 0.02 & 0.03 & 0.03 & 0.30 & 0.30 \\
\hline zshift & $1(1)$ & - & - & 0.12 & 0.07 & 0.10 & 0.04 \\
\hline Total & & 6.7 & 1.6 & 1.8 & 1.1 & 4.4 & 3.6 \\
\hline
\end{tabular}

\subsubsection{Error budget}

According to the optimal estimation method (Rodgers, 2000), the final state $\hat{\boldsymbol{x}}$ satisfies

$\hat{\boldsymbol{x}}=\boldsymbol{x}_{\mathrm{a}}+\hat{G}\left(\boldsymbol{y}-\mathbf{F}(\hat{\boldsymbol{x}}, \boldsymbol{b})+\hat{K}\left(\hat{\boldsymbol{x}}-\boldsymbol{x}_{\mathrm{a}}\right)\right)$,

$\hat{G}=\left(\mathbf{S}_{\mathrm{a}}^{-1}+\hat{K}^{-1} \mathbf{S}_{\epsilon}^{-1} \hat{K}\right)^{-1} \hat{K}^{\mathrm{T}} \mathbf{S}_{\epsilon}^{-1}$,

where $\boldsymbol{x}_{\mathrm{a}}$ is the a priori state vector; $\hat{G}$ is the contribution function, indicating the sensitivity of the retrieval to the measurements; $\hat{K}$ is the weighing function, representing the sensitivity of the measurements to the state vector; $\boldsymbol{y}$ is the observed spectrum and $\mathbf{F}(\hat{\boldsymbol{x}}, \boldsymbol{b})$ is the forward model (with model parameters represented by $\boldsymbol{b}$ ) evaluated in the final state; $\mathbf{S}_{\mathrm{a}}$ is the a priori covariance matrix and $\mathbf{S}_{\varepsilon}$ is the measurement error covariance matrix. If we consider the different uncertainty components, Eq. (6) can be approximated as

$$
\begin{aligned}
\hat{\boldsymbol{x}} & =\boldsymbol{x}_{\mathrm{a}}+\hat{G}\left(\mathbf{F}\left(\boldsymbol{x}_{\mathrm{t}}, \boldsymbol{b}\right)+\varepsilon_{\mathrm{F}}+\varepsilon_{y}+K_{b} \varepsilon_{b}-\mathbf{F}(\hat{\boldsymbol{x}}, \boldsymbol{b})\right. \\
& \left.+\hat{K}\left(\hat{\boldsymbol{x}}-\boldsymbol{x}_{\mathrm{a}}\right)\right)=\boldsymbol{x}_{\mathrm{a}}+\hat{G}\left(\hat{K}\left(\boldsymbol{x}_{\mathrm{t}}-\hat{\boldsymbol{x}}\right)+\hat{K}\left(\hat{\boldsymbol{x}}-\boldsymbol{x}_{\mathrm{a}}\right)\right) \\
& +\hat{G}\left(\varepsilon_{\mathrm{F}}+\varepsilon_{y}+K_{b} \varepsilon_{b}\right),
\end{aligned}
$$

in which $\boldsymbol{x}_{\mathrm{t}}$ is the true state of the atmosphere; $\varepsilon_{\mathrm{F}}$ is the forward model error, $\varepsilon_{y}$ is the measurement noise; $K_{b}$ is the sensitivity of the measurements to the forward model parameters $K_{b}=\partial \mathbf{F}\left(\boldsymbol{x}_{\mathrm{t}}, \boldsymbol{b}\right) / \partial \boldsymbol{b}$. It is worth noting that this equation is approximated using a Newtonian iterative algorithm, which is also subject to an error, but the convergence criterion guarantees that this iteration error gets smaller than the noise error on the spectrum and can be ignored.

We can rewrite Eq. (8) as

$\hat{\boldsymbol{x}}-\boldsymbol{x}_{\mathrm{t}}=\left(\hat{\mathbf{A}}-\mathbf{I}_{n}\right)\left(\boldsymbol{x}_{\mathrm{t}}-\boldsymbol{x}_{\mathrm{a}}\right)+\hat{G}\left(\varepsilon_{\mathrm{F}}+\varepsilon_{y}+K_{b} \varepsilon_{b}\right)$,

where $\hat{\mathbf{A}}=\hat{G} \hat{K}$ is the averaging kernel.
The first term in the right side of Eq. (8) is the smoothing error; the second term contains three parts: the forward model error $\varepsilon_{\mathrm{F}}$, the measurement error $\varepsilon_{y}$ and the forward model parameter error $K_{b} \varepsilon_{b}$. The forward model parameter error comes from the atmospheric (temperature, a priori profiles, pressure, etc.), spectroscopic, geometrical and instrumental parameters, which are not included in the state vector but do have an impact on the forward model calculation. Each error contains both a systematic and a random part.

Tables 2 and 3 list the different contributions to the total average retrieval uncertainty at St Denis and Maïdo, respectively, including smoothing, measurement noise, retrieval parameters (slope, curvature, wavenumber shift, zerolevel offset (zshift), beam parameters, solar line shift, simple phase correction), interfering species, temperature profile, solar zenith angle (SZA) and spectroscopic parameters (line intensity, air-broadened half-width, temperature dependence of the air-broadened half-width). We assume that the measurement and retrieval parameters have very small systematic uncertainties (set to zero in our case) and that the spectroscopic parameters have negligible random errors. Because of the strong $\mathrm{H}_{2} \mathrm{O}$ absorption lines in $\mathrm{CFC}-11$ retrieved microwindow, zshift is included in the state vector for CFC11.

$\mathrm{Sb}$ in Tables 2 and 3 represents the relative uncertainties of the non-retrieved parameters. For temperature, the systematic/random $\mathrm{Sb}$ matrix was created by the mean/standard deviation of the differences between NCEP and the balloon observations at St Denis. The random component is from $2 \mathrm{~K}$ to $4 \mathrm{~K}$ in the vertical range from 0 to $30 \mathrm{~km}$ and about $5 \mathrm{~K}$ above $30 \mathrm{~km}$, and the systematic component is about $2 \mathrm{~K}$ for the whole vertical range. For the target spectroscopic parameters, 7, 1 and $5 \%$ are the relative uncertainties of CFC-11, CFC-12 and HCFC-22, respectively, according to the PLL database. For the $\mathrm{H}_{2} \mathrm{O}$ spectroscopy parameters, the relative 


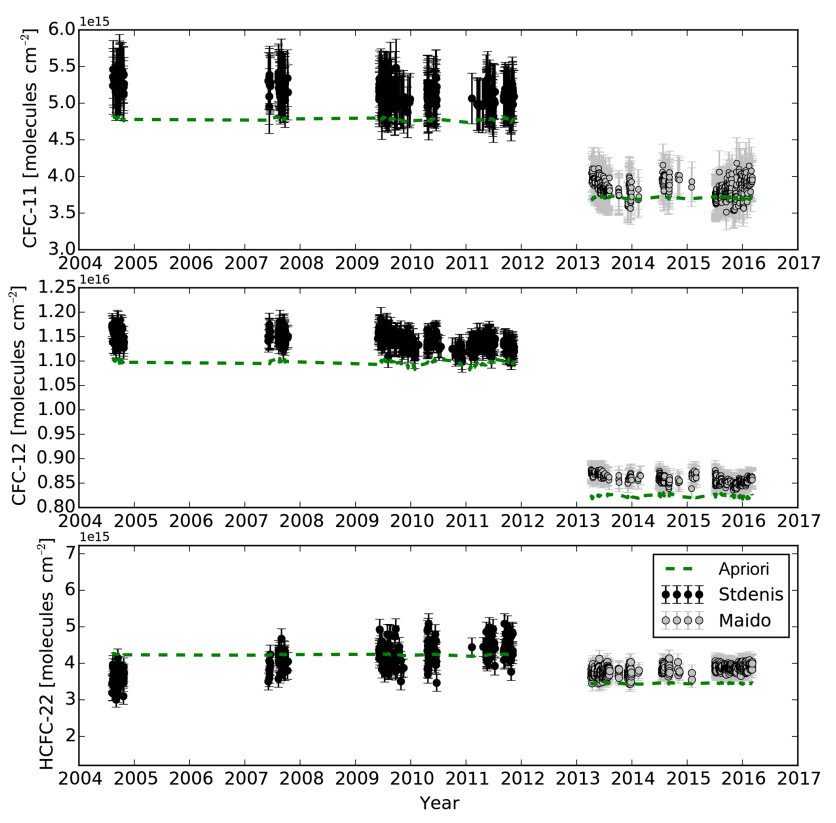

Figure 4. The time series of the total columns and total uncertainties of CFC-11, CFC-12 and HCFC-22 at St Denis (black) and Maïdo (grey), together with the a priori total columns at both sites (green dash lines). The error bar contains both systematic and random uncertainties from SFIT4 retrieval $\left(\sqrt{\varepsilon_{s}^{2}+\varepsilon_{r}^{2}}\right)$.

uncertainty $(10 \%)$ is taken from the HITRAN 2012 data set (Rothman et al., 2013). We assume that the random uncertainty is negligible for all the spectroscopy parameters. For zshift, $1 \%$ is adopted for both the systematic and random uncertainty according to Schneider et al. (2008). Note that zshift is included in the retrieval parameters for CFC-11, but not for CFC-12 and HCFC-22. Therefore, the zshift uncertainty is included in the retrieved parameter error for CFC11 and the zshift uncertainty in Table 2 and 3 is only applied for CFC-11 and HCFC-22 error budget estimations. We assume $5 \%$ for ILS parameters (apodization and phase) relative systematic and random uncertainties. For SZA, the systematic uncertainty is $0.1 \%$ and the random uncertainty is $0.2 \%$, according to the uncertainty estimation from the Pysolar Python software package (http://pysolar.org/).

The total average systematic/random uncertainties associated with the retrieved columns for CFC-11, CFC-12 and HCFC-22 are $7.0 / 2.0 \%, 1.8 / 1.1 \%$ and $4.7 / 4.4 \%$, respectively, at St Denis and 6.7/1.6\%, 1.8/1.1\% and 4.4/3.6\%, respectively, at Maïdo. The systematic uncertainties originate mainly in the uncertainties on the spectroscopic parameters, as well as in the temperature uncertainty. The random uncertainty is dominated by the smoothing error, the uncertainty on the SZA and the measurement noise; especially for HCFC-22, the measurement noise error is very significant due to the narrow and weak absorption of HCFC-22 (see the left bottom panel in Fig. 1).

\subsection{Time series of FTIR measurements and SMO data}

Figure 4 shows the time series of retrieved total columns of CFC-11, CFC-12 and HCFC-22 at St Denis and Maïdo, together with their uncertainties (in unit of molecules $\mathrm{cm}^{-2}$ ). Although the retrievals use the same database of spectra, the numbers of successful retrievals for CFC-11, CFC-12 and HCFC-22 are different. The FTIR retrievals are filtered according to the root mean square (RMS) of the residuals: only retrievals with a RMS smaller than 1.0 (St Denis) and 0.6 (Maïdo) are kept in the analysis. Figure 4 indicates that the time series of CFC-12 has the largest data density, because the $1160.2-1161.4 \mathrm{~cm}^{-1}$ microwindow falls in the middle of the spectrum with high $S / N$, while the microwindows $830.0-860.0 \mathrm{~cm}^{-1}$ (CFC-11) and $828.6-831.0 \mathrm{~cm}^{-1}$ (HCFC-22) lie in the edge of the spectrum, with lower $S / N$ due to the optical filter shape. Figure 4 also shows that there is an offset between the total columns of all three species at St Denis and Maïdo, since the altitude of St Denis ( $85 \mathrm{~m}$ a.s.1.) is much lower than that of Maïdo (2155 m a.s.l.).

We plot in Fig. 5 the column-averaged dry-air mole fractions at St Denis and Maïdo. The column-averaged dry-air mole fraction is the ratio of the column of the target gas with the dry-air column derived from the pressure. Also shown for comparison in Fig. 5 are the in situ and flask daily mean measurements at SMO. We use the Chromatograph for Atmospheric Trace Species (CATS) in situ daily mean data for CFC-11 and CFC-12 (http://www.esrl.noaa. gov/gmd/hats/insitu/cats/) and the flask data for HCFC-22 (Montzka et al., 1993). The precision of the in situ and flask measurements is about a few of tenths of a ppt for CFC11, CFC-12 and HCFC-22 (Montzka et al., 1993). Our FTIR measurements capture the main trends of these species very well, but the scatters observed in the FTIR measurements are much larger than in the in situ measurements mainly due to the larger uncertainties of the FTIR measurements. The FTIR retrievals are also associated with the scatter on the air column (e.g., due to tropopause shifts). The column-averaged dry-air mole fractions of CFC-11 and CFC-12 are lower than the in situ measurements while the column-averaged dry-air mole fraction of HCFC-22 is a bit larger than the in situ measurements. Keep in mind that the SMO is not located at the same place as our FTIR sites.

Note that for CFC-12, it seems that there is an offset between the column-averaged dry-air mole fractions at St Denis and Maïdo, compared with SMO in situ measurements. Since CFC-12 mixes well within 0-20 km (see Fig. 2), the offset cannot be explained by the different pressures at two sites. The offset maybe caused by the systematic retrieval errors and should be taken into account when doing the trend analysis with the combined St Denis and Maïdo data. 

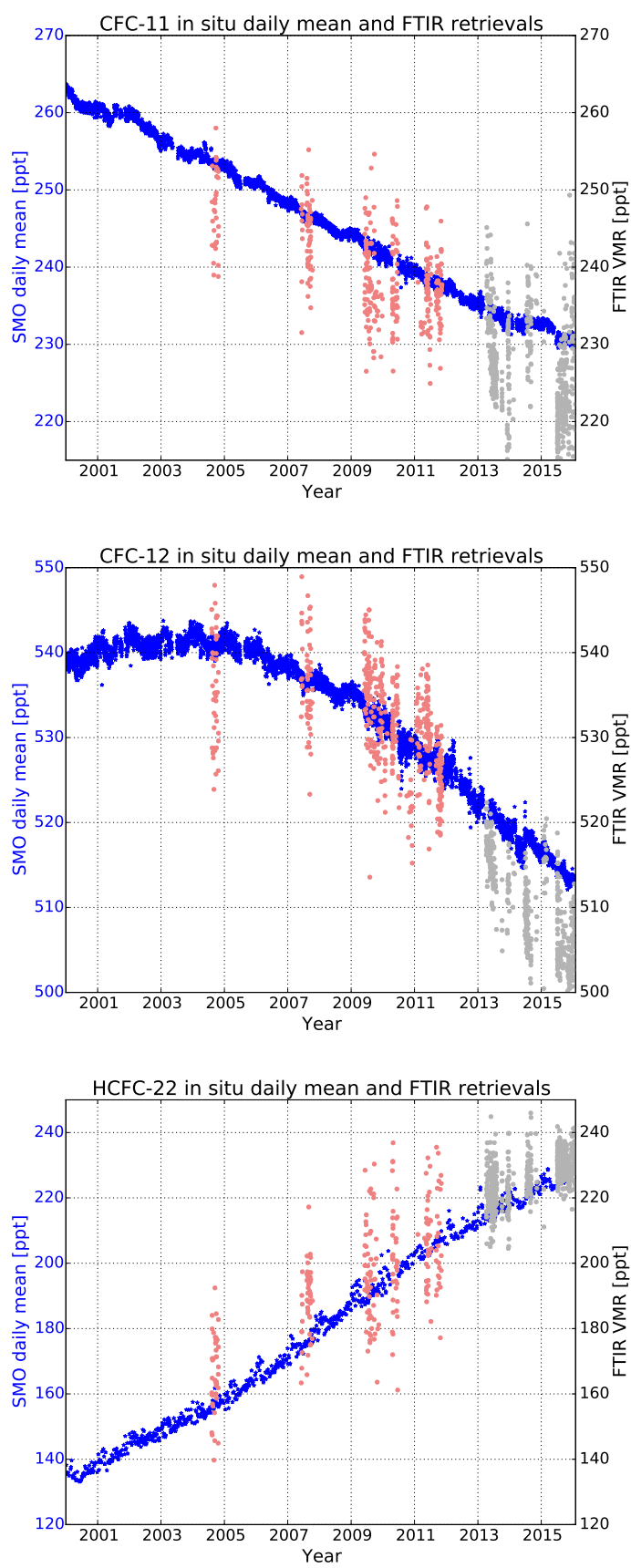

Figure 5. In situ daily mean (CFC-11 and $\mathrm{CFC}-12)$ and flask pair measurements (HCFC-22) at SMO site (blue) and individual FTIR column-averaged dry-air mole fractions at St Denis (light coral) and Maïdo (grey). Upper: CFC-11; middle: CFC-12; bottom: HCFC-22.

\section{Comparison with MIPAS data}

\subsection{MIPAS introduction}

ENVISAT was successfully launched into space on 1 March 2002 carrying several sensors, including MIPAS, a cryogenic limb emission FTS which observes many trace gases from a wide spectrum covering $865-2410 \mathrm{~cm}^{-1}$ (Fischer and Oelhaf, 1996). The mission ended on 8 April 2012. From July 2002 to March 2004, MIPAS was operated in full spectral resolution (FR) mode (spectral resolution: $0.05 \mathrm{~cm}^{-1}$ ), covering the altitude range from 6 to $68 \mathrm{~km}$. Due to the failure of one of the interferometer slides, MIPAS was operated with a reduced spectral resolution $\left(0.121 \mathrm{~cm}^{-1}\right)$, the so-called RR mode, starting January 2005 . The RR mode covers the altitude range from 6 to $70 \mathrm{~km}$ (Fischer et al., 2008). The atmospheric distributions of CFC-11, CFC-12 and HCFC-22 used in this study were derived using the MIPAS level-2 data processor at the Institut für Meteorologie und Klimaforschung-Instituto de Astrofísica de Andalucía (von Clarmann et al., 2003). Data versions V5H (FR) and V5R (RR) were used here (https://www.imk-asf. kit.edu/english/308.php). The retrieval windows of MIPAS are $831.0-853.0 \mathrm{~cm}^{-1}$ for CFC-11, $915.0-925.0 \mathrm{~cm}^{-1}$ for CFC-12 and 803.50-804.75, 808.25-809.75, 820.50-821.12 and $828.75-829.50 \mathrm{~cm}^{-1}$ for HCFC-22. A dedicated spectroscopic database was applied for MIPAS retrieval (Flaud and Teffo, 2003). The detailed MIPAS CFCs retrieval strategies can be found in previous publications (Kellmann et al., 2012; Chirkov et al., 2016); all the products have been validated to some degree by comparison with other space experiments, airborne in situ instruments, ground-based measurements or independent ENVISAT MIPAS analyses (Hoffmann et al., 2008; Eckert et al., 2016). The MIPAS CFC-11, CFC-12 and HCFC-22 retrievals are sensitive to the troposphere and the whole stratosphere (Kellmann et al., 2012; Chirkov et al., 2016) and the DOFS of CFC-11, CFC-12 and HCFC-22 above Réunion Island are about 5, 7 and 4, respectively, for FR data and 7, 11 and 5, respectively, for RR data.

\subsection{Vertical profile comparison}

There is no temporal overlap between MIPAS data and Maïdo measurements, so the MIPAS footprints within $\pm 2^{\circ}$ latitude, $\pm 5^{\circ}$ longitude around St Denis are selected to compare with the St Denis FTIR measurements. The overpass times of MIPAS above Réunion Island are around 06:30 and 18:30 UTC due to the sun-synchronous orbit of ENVISAT. As the FTIR measurements are recorded only during daytime, the MIPAS data around 06:30 UTC are chosen in the following analysis.

Figure 6 shows the comparison of averaged profiles between FTIR measurements and MIPAS data. The individual FTIR-MIPAS data pair was selected when the FTIR measurement and the MIPAS observation were collocated within $\pm 3 \mathrm{~h}$ around 06:30 UTC on the same day. If more than one MIPAS data point was found on a given day, the closest (in geodetic distance) MIPAS data point was taken. If more than one FTIR measurement exists on a given day, each FTIR measurement together with the closest MIPAS data point will be taken as one individual data pair. In total, there are 60,86 and 50 FTIR-MIPAS data pairs for CFC-11, CFC-12 and 
Table 4. The number of collocated MIPAS-FTIR pairs, bias and standard deviation (SD) of the relative differences ((MIPAS - FTIR) $/$ FTIR $\times 100 \%$ ) between the partial columns (6$30 \mathrm{~km}$ ) of MIPAS (both the raw and smoothed data) and FTIR, together with the mean random and systematic uncertainties of the FTIR partial columns and the retrieval error of the MIPAS data (in $\%)$.

\begin{tabular}{lrrr}
\hline & CFC-11 & CFC-12 & HCFC-22 \\
\hline Number of data pairs & 60 & 86 & 50 \\
Bias_raw & -4.4 & -3.3 & 0.18 \\
SD_raw & 4.7 & 4.5 & 5.2 \\
Bias_smoothed & -4.3 & -2.9 & -0.7 \\
SD_smoothed & 4.4 & 4.6 & 4.8 \\
FTIR PC random error & 4.2 & 3.5 & 7.6 \\
FTIR PC systematic error & 10.5 & 2.6 & 7.1 \\
MIPAS PC retrieval error & 4.1 & 4.3 & 5.0 \\
\hline
\end{tabular}

HCFC-22, respectively. It is worth noting that, to account for the sensitivity of the retrieval to the true profiles and to take into account the low vertical resolution of the FTIR retrieved profiles, the MIPAS profile $\hat{\boldsymbol{x}}_{\text {MIPAS }}$ is smoothed by the FTIR

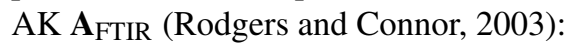

$\hat{\boldsymbol{x}}_{\mathrm{MIPAS}}^{\prime}=\boldsymbol{x}_{\mathrm{FTIR}}^{\text {a priori }}+\mathbf{A}_{\mathrm{FTIR}}\left(\hat{\boldsymbol{x}}_{\mathrm{MIPAS}}-\boldsymbol{x}_{\mathrm{FTIR}}^{\text {a priori }}\right)$,

where $\boldsymbol{x}_{\mathrm{FTIR}}^{\text {apriori }}$ is the FTIR a priori profile and $\hat{\boldsymbol{x}}_{\text {MIPAS }}^{\prime}$ is the MIPAS profile after smoothing correction is applied. The MIPAS profile was interpolated onto the FTIR retrieval grids (keeping the total column unchanged). Figure 6 mainly focuses on the vertical range from 6 to $30 \mathrm{~km}$, because there are not any MIPAS measurements below $6 \mathrm{~km}$ (Fischer et al., 2008) and the FTIR sensitivity is very weak above $30 \mathrm{~km}$ (see Fig. 1). In addition, the low FTIR sensitivity above $30 \mathrm{~km}$ leads to a very small relative difference (less than $1 \%$ ) between the smoothed MIPAS and FTIR $(($ MIPAS - FTIR) $/$ FTIR $\times 100 \%)$ above $30 \mathrm{~km}$ for all three species (see right panels in Fig. 6). Since the FTIR retrievals have very poor vertical resolution, the "oscillation" of the profiles of the relative difference between FTIR and MIPAS could be caused by the FTIR retrievals. Anyhow, for CFC-11, the FTIR concentration is larger than the smoothed MIPAS concentration value between 6 and $30 \mathrm{~km}$ : the largest difference is of order $-7 \%$ around $15 \mathrm{~km}$. For CFC-12, the FTIR retrieval is larger below $14 \mathrm{~km}$ and smaller above $14 \mathrm{~km}$ than the smoothed MIPAS data. The peaks are around $6 \mathrm{~km}$ $(-8 \%)$ and $18 \mathrm{~km}(2 \%)$. For HCFC-22, the FTIR retrieval is very close to the smoothed MIPAS data: the relative difference is within $\pm 5 \%$ between 6 and $30 \mathrm{~km}$.

\subsection{Partial column comparison}

In this section, we compare the MIPAS and St Denis FTIR partial columns (PC) from 6 to $30 \mathrm{~km}$, for the same collocated pairs as in Sect. 3.2. The DOFS of the partial
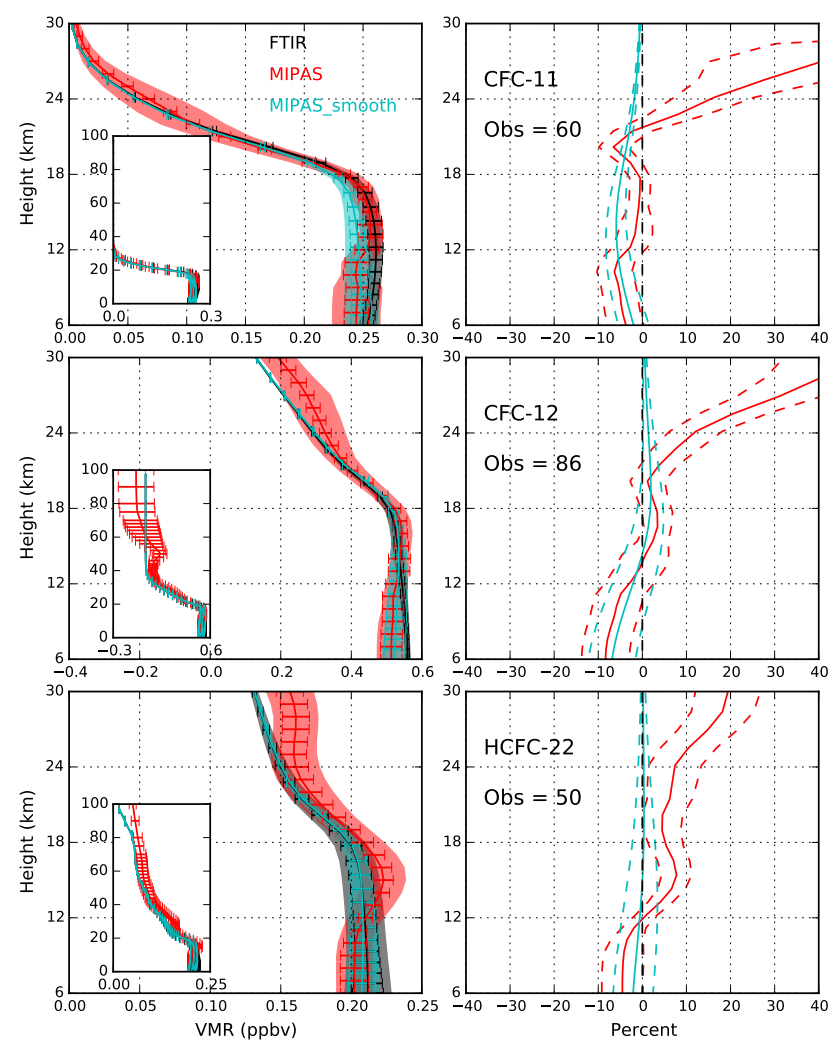

Figure 6. Left panel, for each target species (from top to bottom: CFC-11, CFC-12 and HCFC-22): averaged target species mixing ratio profile, random uncertainty (error bar) and the standard deviation of all the co-existing data pairs (shade area) for FTIR (in black) and for MIPAS (in red: raw data; in sky blue: after smoothing with the corresponding FTIR averaging kernel). The profiles (from 0 to $100 \mathrm{~km}$ ) are also manifested in the left panels. Right panel, for each target species, averaged relative difference between MIPAS and FTIR ((MIPAS - FTIR) / FTIR $\times 100 \%)$ (solid lines), along with the standard deviation (dash lines).

columns of CFC-11, CFC-12 and HCFC-22, respectively, are $0.6 \pm 0.1,0.9 \pm 0.1$ and $0.6 \pm 0.1$. Table 4 exhibits the statistical values of the comparison: relative bias and standard deviation of the difference between the MIPAS (raw and smoothed) and FTIR, together with the partial column uncertainties from both data sets. The largest mean relative bias is found for CFC-11 (-4.3\%), showing that the FTIR partial columns are larger than the MIPAS ones, which is probably caused by the large systematic error of FTIR CFC-11 retrievals $(10.5 \%)$. For CFC-12, the bias is $-2.7 \%$, which is also within the uncertainty budget of combined data sets. The lowest relative bias is found for HCFC-22 $(-0.7 \%)$, but the standard deviation is still large $(4.8 \%)$ because of the large FTIR retrieval errors (7.6/7.1\%) and MIPAS retrieval error $(5.0 \%)$. Overall, the biases and standard deviations between the two data sets lie within the uncertainty budgets for the three species. 

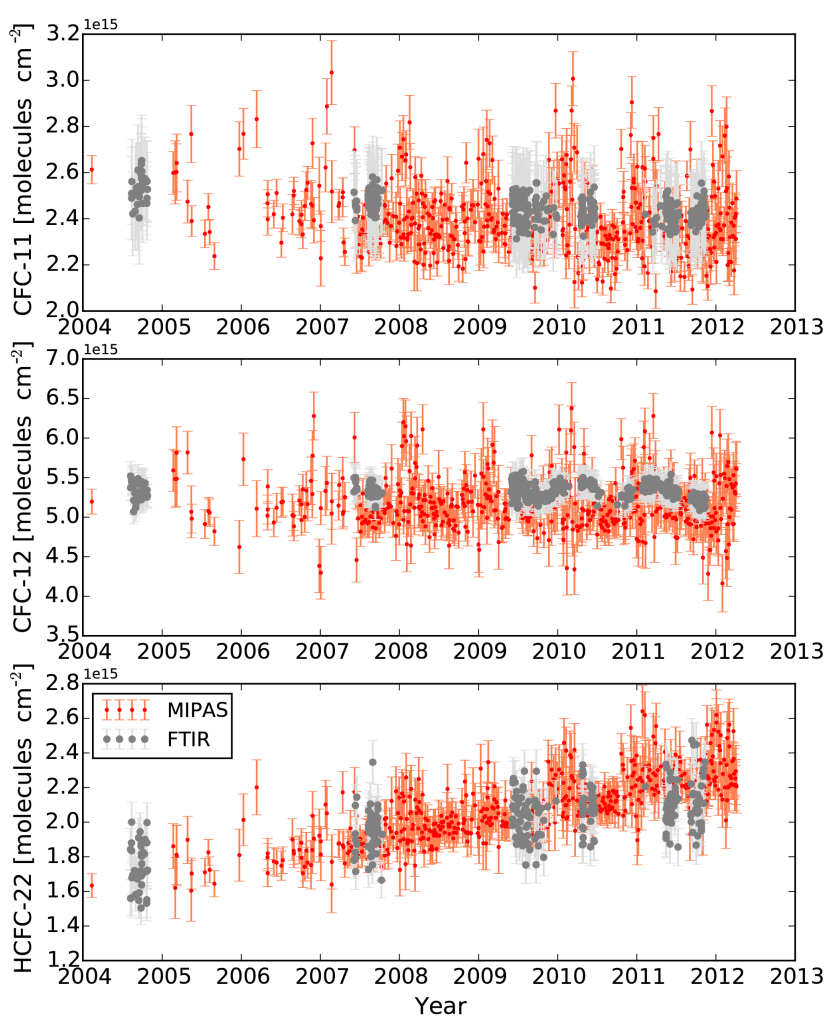

Figure 7. The time series of the individual partial columns (6$30 \mathrm{~km}$ ) of CFC-11, CFC-12 and HCFC-22 from St Denis FTIR measurements (grey) and raw MIPAS data (red). Error bars represent the retrieval errors.

Figure 7 shows the time series of the individual partial columns of CFC-11, CFC-12 and HCFC-22 FTIR measurements at St Denis (grey) along with the raw MIPAS data (red). The smoothed MIPAS data are not shown here because more than half of MIPAS data do not correspond with an individual FTIR measurement within 1 day or even 1 week, and the differences between partial columns of smoothed and unsmoothed data are within $1.0 \%$. Note that the bias between the raw MIPAS and FTIR data also contains the smoothing error, but the bias already lies within the uncertainty budget even without smoothing error (see Table 4). The individual partial columns of MIPAS and FTIR data, based on the respective original time series, are in a good agreement.

\subsection{Trends and seasonal cycles comparisons}

\subsubsection{Method}

To derive the secular trends from the FTIR and in situ measurements daily means $Y(t)$, with $t$ the time in fractional year, we use a regression model that includes a Fourier se- ries (third order) to describe the seasonal cycle:

$Y(t)=$

$A_{0}+A_{1} \cdot t+\sum_{k=1}^{3}\left(A_{2 k} \cos (k \pi t)+A_{2 k+1} \sin (2 k \pi t)\right)+\varepsilon(t)$,

where $A_{0}$ is the intercept at $t=0, A_{1}$ is the secular (annual) trend, $A_{2}$ to $A_{7}$ are the seasonal cycle parameters and $\varepsilon(t)$ is the residuals between the observations and the model. The auto-correlation in the residuals must be taken into account to avoid the underestimation of trend uncertainties. We follow the approach of Santer et al. (2000) which, by combining their Eqs. (3)-(6), leads us to the following corrected uncertainty $\sigma_{\mathrm{c}}$ on the regression parameters:

$\sigma_{c}=\sigma_{\mathrm{d}} \frac{(n-2)}{\left(n_{\mathrm{e}}-2\right)}$,

where $\sigma_{\mathrm{d}}$ is the uncertainty directly provided by the regression model, $n$ the number of daily means in the $Y(t)$ time series, and $n_{\mathrm{e}}$ the effective sampling size.

$n_{\mathrm{e}}=n \frac{1-r}{1+r}$,

where $r$ is the auto-correlation, with a time lag of 1 , in the residuals.

\subsubsection{Results and discussions}

Since the Maïdo measurements only cover about 3 years, we cannot perform trend analysis on only Maïdo data. Therefore, we use the total columns at Maïdo in combination with the St Denis partial columns calculated at the altitude of Maïdo $(2.155-100 \mathrm{~km})$ to derive the trends of CFC-11, CFC-12 and HCFC-22 at Réunion Island for the period 2004-2016.

Table 5 gives the annual percent changes and their uncertainties of CFC-11, CFC-12 and HCF-22 (\% year $\left.{ }^{-1}\right)$ from both FTIR at Réunion Island (combination of St Denis partial column $(2.155-100 \mathrm{~km})$ and Maïdo total column) and from the in situ and flask measurements at SMO. The MIPAS (2004-2011) trends were calculated by $6-30 \mathrm{~km}$ partial column above St Denis. To better compare with MIPAS data, the trends of St Denis partial column $(6-30 \mathrm{~km})$ are calculated separately. The trends from ACE-FTS and Jungfraujoch FTIR measurements in Carpenter et al. (2014) are also listed in Table 5 for comparison. The ACE-FTS (2004-2010) trends were determined by averaging the mixing ratios in molecule-dependent altitude ranges within tropical occultation $\left(30^{\circ} \mathrm{N}-30^{\circ} \mathrm{S}\right)$ and Jungfraujoch is the total columns of FTIR measurements. The annual percent change, in this study, is defined as the ratio of the annual change to the mean of all the measurements that are used to do the trend analysis.

For CFC-11, the annual change of the combined FTIR partial columns $(2.155-100 \mathrm{~km})$ at St Denis and total columns at Maïdo (2004-2016) is very close to the SMO measurements 
Table 5. The annual percent changes (in $\%$ year $^{-1}$, relative to the mean of data used in the trend analysis) and uncertainties of FTIR total columns of CFC-11, CFC-12 and HCF-22 at St Denis (2004-2011) and of the combined partial columns (2.155-100 km) at St Denis along with the total columns at Maïdo (2004-2016 for CFC-11 and HCFC-22; 2009-2016 for CFC-12). The trends from in situ and flask measurements at SMO are also given for the same time periods. The trends from St Denis partial column (6-30 km) and MIPAS partial column (6-30 km) from 2004 to 2011 are also listed in the table. The trends observed by ACE-FTS (2004-2010) and by the ground-based FTIR at Jungfraujoch (2004-2010) in \% year ${ }^{-1}$ relative to the 2007 annual mean are taken from Carpenter et al. (2014) as described in the text.

\begin{tabular}{lrrrrl}
\hline Data set & Time range & CFC-11 & CFC-12 & HCFC-22 & Reference \\
\hline St Denis (2.155-100 km) & $2004-2016$ & $-0.86 \pm 0.12$ & - & $2.84 \pm 0.06$ & \\
+ Maïdo & $2009-2016$ & - & $-0.76 \pm 0.05$ & - & \\
SMO & $2004-2016$ & $-0.87 \pm 0.04$ & - & $3.46 \pm 0.05$ & \\
& $2009-2016$ & - & $-0.60 \pm 0.02$ & - & \\
\hline St Denis (6-30 km) & $2004-2011$ & $-0.67 \pm 0.15$ & $-0.24 \pm 0.14$ & $3.09 \pm 0.17$ & \\
MIPAS (6-30 km) & $2004-2011$ & $-0.80 \pm 0.34$ & $-0.20 \pm 0.32$ & $4.05 \pm 0.30$ & \\
SMO & $2004-2011$ & $-0.89 \pm 0.01$ & $-0.37 \pm 0.08$ & $4.04 \pm 0.06$ & \\
\hline ACE-FTS & $2004-2010$ & $-0.9 \pm 0.1$ & $-0.4 \pm 0.1$ & $3.7 \pm 0.1$ & Brown et al. (2011) \\
Jungfraujoch & $2004-2010$ & $-0.99 \pm 0.10$ & $-0.38 \pm 0.07$ & $3.52 \pm 0.08$ & Zander et al. (2008) \\
\hline
\end{tabular}

$\left(-0.86 \pm 0.12\right.$ vs. $-0.87 \pm 0.04 \%$ year $\left.^{-1}\right)$. The partial column $(6-30 \mathrm{~km})$ annual change at St Denis (2004-2011) is $-0.67 \pm 0.15 \%$ year $^{-1}$, which is in agreement, within uncertainties, with the one from MIPAS partial column data $\left(-0.80 \pm 0.34 \%\right.$ year $\left.^{-1}\right)$ but weaker than the one derived from SMO measurements $\left(-0.89 \pm 0.01 \%\right.$ year $\left.^{-1}\right)$. It is also weaker than the trends reported by ACE-FTS (Brown et al., 2011) and Jungfraujoch FTIR (Zander et al., 2008) measurements.

For CFC-12, Fig. 5 shows that its concentration has a significant trend change around 2004 (increasing before 2004 and decreasing after); therefore, it is relevant, in order to capture the most recent trend, to select the data after 2009 to do the trend analysis. The annual change of the combined partial columns $(2.155-100 \mathrm{~km})$ at St Denis and total columns at Maïdo (2009-2016) is stronger than that derived from the SMO measurements $(-0.76 \pm 0.05$ vs. $-0.60 \pm 0.02 \%$ year $^{-1}$ ). As mentioned in Sect. 2.3 , it seems that there is an offset between the column-averaged dry-air mole fractions at St Denis and Maïdo. The Maïdo data are systematically lower than the St Denis data, leading to a larger decreasing trend with the combined data. Using the combination of St Denis and Maïdo may therefore overestimate the annual trend of CFC-12. For the comparisons with MIPAS, we show in Table 5 that the FTIR partial column (6-30 km) annual change at St Denis (2004-2011) is $-0.24 \pm 0.14 \%$ year $^{-1}$, while the MIPAS annual change is $-0.20 \pm 0.32 \%$ year $^{-1}$, which is not statistically significant. The FTIR 2004-2011 trend is also weaker than the one derived from SMO measurements $\left(-0.37 \pm 0.08 \%\right.$ year $\left.^{-1}\right)$ but in agreement within the estimated uncertainties. It is also in agreement with the ACE-FTS and Jungfraujoch reported trends.
For HCFC-22 the trend of the combined partial columns $(2.155-100 \mathrm{~km})$ at St Denis and total columns at Maïdo (2004-2016) is smaller than that of the SMO measurements $\left(2.84 \pm 0.06\right.$ vs. $3.46 \pm 0.05 \%$ year $\left.^{-1}\right)$. The annual change of St Denis partial columns of $6-30 \mathrm{~km}$ $\left(3.09 \pm 0.17 \%\right.$ year $\left.^{-1}\right)$ is also smaller than the one derived from MIPAS measurements $\left(4.05 \pm 0.30 \%\right.$ year $\left.^{-1}\right)$ and from SMO measurements $\left(4.04 \pm 0.06 \%\right.$ year $\left.^{-1}\right)$. The trend of FTIR measurements at St Denis is closer to the trends reported from ACE-FTS data and Jungfraujoch measurements for approximately the same period, but still not in agreement within the uncertainties.

Figure 8 shows the seasonal cycles of CFC-11, CFC-12 and HCFC-22 based on FTIR (both St Denis and Maïdo) partial columns of 6-30 km (grey) and MIPAS partial columns of $6-30 \mathrm{~km}$ (red). The mean of the measurements for each month during the 2004-2016 period for FTIR measurements and 2004-2011 for MIPAS data, after subtraction of the trend, is shown, together with the $2 \sigma$ error on the mean $(2 \sigma / \sqrt{n} ; n$ being the number of measurements for each month). Note that the annual cycles for CFC-12 is estimated based on the whole time series (and not only for the 20092016 period) to enhance the precision on the annual cycle by using all available data. The seasonal cycles of CFC-11, CFC-12 and HCFC-22 from both data sets show similar variation: concentration is highest in February-April and lowest in August-October. For CFC-12, the $2 \sigma$ error of FTIR seasonal cycle is much less than that of MIPAS data, according to the smaller scatter of FTIR measurements (see Fig. 7). The seasonal cycles of CFC-11, CFC-12 and HCFC-22 at Jungfraujoch also show similar pattern: high concentrations in summer-autumn and low in winter-spring (Mahieu et al., 2015). 

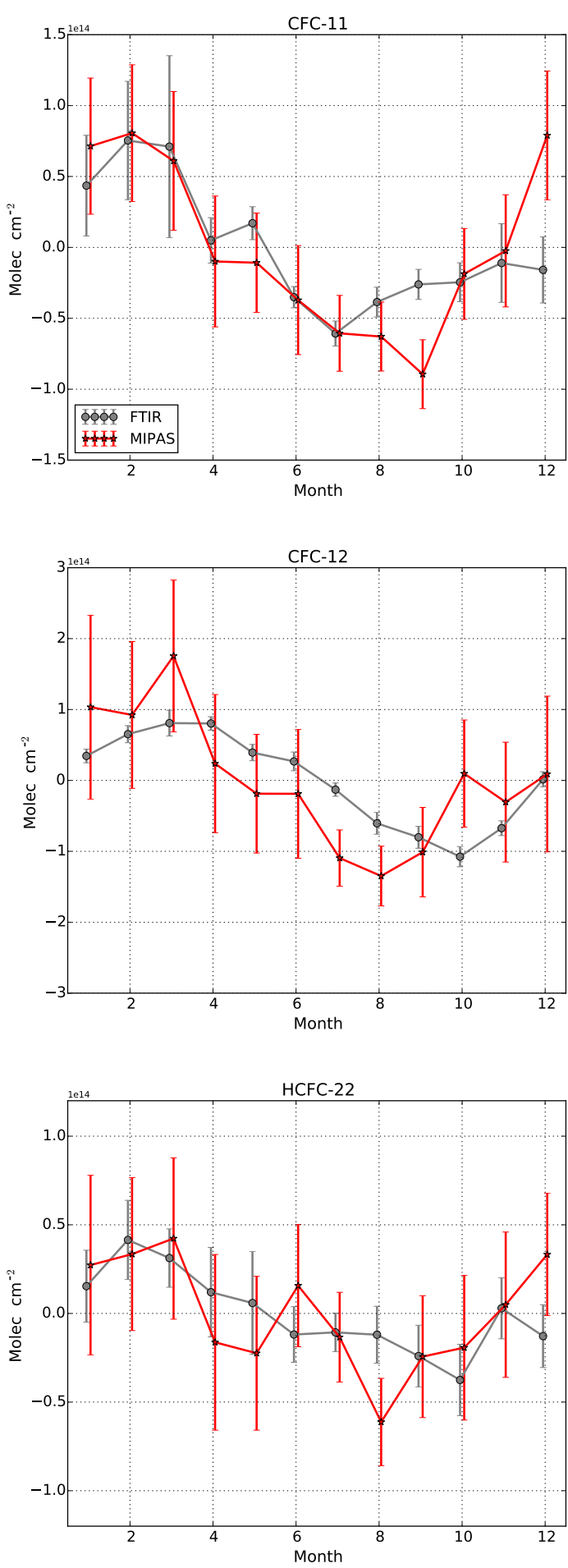

Figure 8. Seasonal cycles of CFC-11, CFC-12 and HCFC-22 based on FTIR measurements (grey) and MIPAS data (red). The mean of the measurements for each month during the 2004-2016 period for FTIR measurements and 2004-2011 for MIPAS data, after subtraction of the trend, is shown as circle (FTIR) and asterisk (MIPAS), together with the $2 \sigma$ error on the mean $(2 \sigma / \sqrt{n} ; n$ being the number of measurements for each month).

\section{Summary}

CFC-11, CFC-12 and HCFC-22 mixing ratio profiles were retrieved at Réunion Island from St Denis and Maïdo groundbased solar absorption FTIR measurements between 2004 and 2016. The retrieval microwindows are carefully selected to minimize the interfering absorptions from other species. The AKs of CFC-11, CFC-12 and HCFC-22 are very similar, and the retrieved information comes mainly from the troposphere and lower stratosphere with low vertical resolution. As expected as a response to the Montreal Protocol, negative trends of total columns of CFC-11 and CFC-12 and a positive trend of HCFC-22 were observed at St Denis and Maïdo, which is in good agreement with the in situ surface data and other remote sensing results (e.g., SMO in situ and flask measurements and Jungfraujoch FTIR data, respectively). The observed FTIR total column trends above St Denis between 2004 and 2011 are $-0.69 \pm 0.15 \%$ year $^{-1}$ for CFC-11, $-0.26 \pm 0.10 \%$ year $^{-1}$ for CFC-12 and $3.09 \pm 0.17 \%$ year $^{-1}$ for HCFC-22. The trends of combined FTIR partial columns $(2.155-100 \mathrm{~km})$ at St Denis and total columns at Maïdo are $-0.86 \pm 0.12 \%$ year $^{-1}$ for CFC-11 and $2.84 \pm 0.06 \%$ year $^{-1}$ for HCFC-22 between 2004 and 2016, and $-0.76 \pm 0.05 \%$ year $^{-1}$ for CFC- 12 between 2009 and 2016. These trends are consistent with the ones observed at SMO for CFC-11 $\left(-0.87 \pm 0.04 \%\right.$ year $\left.^{-1}\right)$, but slightly smaller for HCFC-22 $\left(3.46 \pm 0.05 \%\right.$ year $\left.^{-1}\right)$ and larger for CFC-12 $\left(-0.60 \pm 0.02 \%\right.$ year $\left.^{-1}\right)$.

The FTIR measurements were also compared with collocated MIPAS/ENVISAT data around St Denis. There are 60, 86 and 50 FTIR-MIPAS collocated data pairs for CFC$11, \mathrm{CFC}-12$ and HCFC-22 within $\pm 2^{\circ}$ latitude, $\pm 5^{\circ}$ longitude and $\pm 3 \mathrm{~h}$ around 06:30 UTC. The differences between FTIR and smoothed MIPAS profiles from 6 to $30 \mathrm{~km}$ altitude are within $\pm 10 \%$ for CFC-11 and CFC-12 and $\pm 5 \%$ for HCFC- 22 . The relative biases and standard deviations of the differences between the partial columns $(6-30 \mathrm{~km})$ of smoothed MIPAS and FTIR are $-4.3 \pm 4.4$, $-2.9 \pm 4.6$ and $-0.7 \% \pm 4.8 \%$ for CFC- $11, \mathrm{CFC}-12$ and HCFC-22, respectively, which lie within the error budgets from both data sets. Overall, the time series of MIPAS partial columns show a good agreement with the St Denis FTIR partial column data. The trend analysis based on St Denis FTIR (2004-2011) partial columns (6-30 km) has also compared with MIPAS data (2004-2011) in the same vertical range. For CFC-11, the annual change at St Denis is $-0.67 \pm 0.15 \%$ year $^{-1}$, which is in agreement, within uncertainties, with the one from MIPAS partial column data $\left(-0.80 \pm 0.34 \%\right.$ year $\left.^{-1}\right)$. For CFC-12, the annual change at St Denis is $-0.24 \pm 0.14 \%$ year $^{-1}$, while the MIPAS annual change is $-0.20 \pm 0.32 \%$ year $^{-1}$, which is not statistically significant. For HCFC-22, the annual change of St Denis partial columns $\left(3.09 \pm 0.17 \%\right.$ year $\left.^{-1}\right)$ is smaller than the one derived from MIPAS measurements $\left(4.05 \pm 0.30 \%\right.$ year $\left.^{-1}\right)$, and they are not in agreement within the trend uncertainties. 
The season cycles of CFC-11, CFC-12 and HCFC-22 from both FTIR measurements and MIPAS data show a similar pattern: concentration is highest in February-April and lowest in August-October.

\section{Data availability}

The FTIR CFC-11, CFC-12 and HCFC-22 retrievals at St Denis and Maïdo are not publicly available yet because they are not standard NDACC species. To obtain access to site data, please contact the author or BIRA-IASB FTIR group. MIPAS/ENVISAT versions V5H (FR) and V5R (RR) Level 2 CFC-11, CFC-12 and HCFC-22 data are publicly available from KIT/IMK (https://www.imk-asf.kit.edu/english/ 308.php). The SMO HATS in situ CFC-11 and CFC-12 data are publicly available from NOAA (http://www.esrl.noaa. gov/gmd/hats/insitu/cats/cats_conc.html). The SMO HATS flask sampling HCFC-22 data are publicly available from NOAA (http://www.esrl.noaa.gov/gmd/hats/gases/HCFC22. html).

Acknowledgements. This work is supported by the National Natural Science Foundation of China (41575034). The authors wish to thank Steve Montzka from NOAA for providing the HCFC-22 flask measurements, the Université de la Réunion, as well as the Belgian Science Policy and AGACC-II project for supporting the NDACC operations in Réunion Island, the MIPAS satellite group at KIT/IMK for the provision of CFC-11, CFC-12 and HCFC-22 MIPAS data. The authors the European Communities, the Région Réunion, CNRS, and Université de la Réunion for their support and contribution in the construction phase of the research infrastructure OPAR (Observatoire de Physique de l'Atmosphère à La Réunion). OPAR is presently funded by CNRS (INSU) and Université de La Réunion, and managed by OSU-R (Observatoire des Sciences de l'Univers à La Réunion, UMS 3365). The authors also want to thank Emmanuel Mahieu, Philippe Demoulin and Stephanie Conway for helpful discussions. Part of this work was performed at Jet Propulsion Laboratory, California Institute of Technology, under contact with NASA.

Edited by: H. Maring

Reviewed by: O. Garciar and one anonymous referee

\section{References}

Baray, J.-L., Courcoux, Y., Keckhut, P., Portafaix, T., Tulet, P., Cammas, J.-P., Hauchecorne, A., Godin Beekmann, S., De Mazière, M., Hermans, C., Desmet, F., Sellegri, K., Colomb, A., Ramonet, M., Sciare, J., Vuillemin, C., Hoareau, C., Dionisi, D., Duflot, V., Vérèmes, H., Porteneuve, J., Gabarrot, F., Gaudo, T., Metzger, J.-M., Payen, G., Leclair de Bellevue, J., Barthe, C., Posny, F., Ricaud, P., Abchiche, A., and Delmas, R.: Maïdo observatory: a new high-altitude station facility at Reunion Island $\left(21^{\circ} \mathrm{S}, 55^{\circ} \mathrm{E}\right)$ for long-term atmospheric remote sensing and in situ measure- ments, Atmos. Meas. Tech., 6, 2865-2877, doi:10.5194/amt-62865-2013, 2013.

Brown, A. T., Chipperfield, M. P., Boone, C., Wilson, C., Walker, K. A., and Bernath, P. F.: Trends in atmospheric halogen containing gases since 2004, J Quant. Spectrosc. Ra., 112, 2552-2566, doi:10.1016/j.jqsrt.2011.07.005, 2011.

Carpenter, L. J., Reimann, S., Burkholder, J. B., Clerbaux, C., Hall, B. D., Hossaini, R., Laube, J. C., and Yvon-Lewis, S. A.: Update on ozone-depleting substances (ODSs) and other gases of interest to the Montreal protocol, Scientific Assessment of Ozone Depletion: 2014, World Meteorological Organization, 2014.

Chirkov, M., Stiller, G. P., Laeng, A., Kellmann, S., von Clarmann, T., Boone, C. D., Elkins, J. W., Engel, A., Glatthor, N., Grabowski, U., Harth, C. M., Kiefer, M., Kolonjari, F., Krummel, P. B., Linden, A., Lunder, C. R., Miller, B. R., Montzka, S. A., Mühle, J., O’Doherty, S., Orphal, J., Prinn, R. G., Toon, G., Vollmer, M. K., Walker, K. A., Weiss, R. F., Wiegele, A., and Young, D.: Global HCFC-22 measurements with MIPAS: retrieval, validation, global distribution and its evolution over 2005-2012, Atmos. Chem. Phys., 16, 3345-3368, doi:10.5194/acp-16-3345-2016, 2016.

Cunnold, D., Weiss, R., Prinn, R., Hartley, D., Simmonds, P., Fraser, P., Miller, B., Alyea, F., and Porter, L.: GAGE/AGAGE measurements indicating reductions in global emissions of $\mathrm{CCl}_{3} \mathrm{~F}$ and $\mathrm{CCl}_{2} \mathrm{~F}_{2}$ in 1992-1994, J. Geophys. Res.-Atmos., 102, 12591269, doi:10.1029/96JD02973, 1997.

Duflot, V., Dils, B., Baray, J. L., De Mazière, M., Attié, J. L., Vanhaelewyn, G., Senten, C., Vigouroux, C., Clain, G., and Delmas, R.: Analysis of the origin of the distribution of $\mathrm{CO}$ in the subtropical southern Indian Ocean in 2007, J. Geophys. Res., 115, D22106, doi:10.1029/2010jd013994, 2010.

Dunse, B., Steele, L., Wilson, S., Fraser, P., and Krummel, P.: Trace gas emissions from Melbourne, Australia, based on AGAGE observations at Cape Grim, Tasmania, 1995-2000, Atmos. Environ., 39, 6334-6344, doi:10.1016/j.atmosenv.2005.07.014, 2005.

Eckert, E., Laeng, A., Lossow, S., Kellmann, S., Stiller, G., von Clarmann, T., Glatthor, N., Höpfner, M., Kiefer, M., Oelhaf, H., Orphal, J., Funke, B., Grabowski, U., Haenel, F., Linden, A., Wetzel, G., Woiwode, W., Bernath, P. F., Boone, C., Dutton, G. S., Elkins, J. W., Engel, A., Gille, J. C., Kolonjari, F., Sugita, T., Toon, G. C., and Walker, K. A.: MIPAS IMK/IAA CFC-11 $\left(\mathrm{CCl}_{3} \mathrm{~F}\right)$ and $\mathrm{CFC}-12\left(\mathrm{CCl}_{2} \mathrm{~F}_{2}\right)$ measurements: accuracy, precision and long-term stability, Atmos. Meas. Tech., 9, 3355-3389, doi:10.5194/amt-9-3355-2016, 2016.

Elkins, J., Thompson, T., Swanson, T., Butler, J., Hall, B., Cummings, S., Fisher, D., and Raffo, A.: Decrease in the growth rates of atmospheric chlorofluorocarbons 11 and 12, Nature, 364, 780783, doi:10.1038/364780a0, 1993.

Fischer, H. and Oelhaf, H.: Remote sensing of vertical profiles of atmospheric trace constituents with MIPAS limb-emission spectrometers, Appl. Opt., 35, 2787-2796, doi:10.1364/AO.35.002787, 1996.

Fischer, H., Birk, M., Blom, C., Carli, B., Carlotti, M., von Clarmann, T., Delbouille, L., Dudhia, A., Ehhalt, D., Endemann, M., Flaud, J. M., Gessner, R., Kleinert, A., Koopman, R., Langen, J., López-Puertas, M., Mosner, P., Nett, H., Oelhaf, H., Perron, G., Remedios, J., Ridolfi, M., Stiller, G., and Zander, R.: MIPAS: an instrument for atmospheric and climate research, Atmos. Chem. Phys., 8, 2151-2188, doi:10.5194/acp-8-2151-2008, 2008. 
Flaud, J.-M. P. C. and Teffo, B. P. A. C. L.: Molecular line parameters for the MIPAS (Michelson Interferometer for Passive Atmospheric Sounding) experiment, J. Atmos. Sol.-Terr. Phy., 16, 172-181, 2003.

Hase, F., Blumenstock, T., and Paton-Walsh, C.: Analysis of the instrumental line shape of high-resolution Fourier transform IR spectrometers with gas cell measurements and new retrieval software, Appl. Opt., 38, 3417-3422, doi:10.1364/AO.38.003417, 1999.

Hoffmann, L. and Riese, M.: Quantitative transport studies based on trace gas assimilation, Adv. Space Res., 33, 1068-1072, doi:10.1016/S0273-1177(03)00592-1, 2004.

Hoffmann, L., Kaufmann, M., Spang, R., Müller, R., Remedios, J. J., Moore, D. P., Volk, C. M., von Clarmann, T., and Riese, M.: Envisat MIPAS measurements of CFC-11: retrieval, validation, and climatology, Atmos. Chem. Phys., 8, 3671-3688, doi:10.5194/acp-8-3671-2008, 2008.

Kellmann, S., von Clarmann, T., Stiller, G. P., Eckert, E., Glatthor, N., Höpfner, M., Kiefer, M., Orphal, J., Funke, B., Grabowski, U., Linden, A., Dutton, G. S., and Elkins, J. W.: Global CFC-11 $\left(\mathrm{CCl}_{3} \mathrm{~F}\right)$ and $\mathrm{CFC}-12\left(\mathrm{CCl}_{2} \mathrm{~F}_{2}\right)$ measurements with the Michelson Interferometer for Passive Atmospheric Sounding (MIPAS): retrieval, climatologies and trends, Atmos. Chem. Phys., 12, 11857-11875, doi:10.5194/acp-12-11857-2012, 2012.

Khosrawi, F., Müller, R., Irie, H., Engel, A., Toon, G., Sen, B., Aoki, S., Nakazawa, T., Traub, W., and Jucks, K.: Validation of CFC-12 measurements from the Improved Limb Atmospheric Spectrometer (ILAS) with the version 6.0 retrieval algorithm, J. Geophys. Res.-Atmos., 109, D06311, doi:10.1029/2003JD004325, 2004.

Ko, M., Newman, P., Reimann, S., Strahan, S., Plumb, R., Stolarski, R., Burkholder, J., Mellouki, W., Engel, A., and Atlas, E.: Lifetimes of stratospheric ozone-depleting substances, their replacements, and related species, SPARC Report No. 6 WCRP15/2013, 2013.

Lashof, D. A. and Ahuja, D. R.: Relative contributions of greenhouse gas emissions to global warming, Nature, 529-531, doi:10.1038/344529a0, 1990

Mahieu, E., Duchatelet, P., Demoulin, P., Walker, K. A., Dupuy, E., Froidevaux, L., Randall, C., Catoire, V., Strong, K., Boone, C. D., Bernath, P. F., Blavier, J.-F., Blumenstock, T., Coffey, M., De Mazière, M., Griffith, D., Hannigan, J., Hase, F., Jones, N., Jucks, K. W., Kagawa, A., Kasai, Y., Mebarki, Y., Mikuteit, S., Nassar, R., Notholt, J., Rinsland, C. P., Robert, C., Schrems, O., Senten, C., Smale, D., Taylor, J., Tétard, C., Toon, G. C., Warneke, T., Wood, S. W., Zander, R., and Servais, C.: Validation of ACEFTS v2.2 measurements of $\mathrm{HCl}, \mathrm{HF}, \mathrm{CCl}_{3} \mathrm{~F}$ and $\mathrm{CCl}_{2} \mathrm{~F}_{2}$ using space-, balloon- and ground-based instrument observations, Atmos. Chem. Phys., 8, 6199-6221, doi:10.5194/acp-8-6199-2008, 2008.

Mahieu, E., Rinsland, C. P., Gardiner, T., Zander, R., Demoulin, P., Chipperfield, M. P., Ruhnke, R., Chiou, L. S., and De Mazière, M.: Recent trends of inorganic chlorine and halogenated source gases above the Jungfraujoch and Kitt Peak stations derived from high-resolution FTIR solar observations, EGU General Assembly 2010, Katlenburg-Lindau, Germany, 2-7 May 2010, European Geophysical Society, 2010.

Mahieu, E., O’Doherty, S., Reimann, S., Vollmer, M., Bader, W., Bovy, B., Lejeune, B., Demoulin, P., Roland, G., and Servais, C.: First retrievals of HCFC-142b from ground-based high res- olution FTIR solar observations: application to high altitude Jungfraujoch spectra, EGU General Assembly 2013, KatlenburgLindau, Germany, 7-12 April 2013, publisher, European Geophysical Society, 2013.

Mahieu, E., Bader, W., and Franco, B.: Recent results derived from regular ground-based FTIR observations at the Jungfraujoch and other NDACC stations, ACE Science Team Meeting, 20-21 May, 2015.

Molina, M. J. and Rowland, F. S.: Stratospheric sink for chlorofluoromethanes: chlorine atom-catalysed destruction of ozone, Nature, 249, 810-812, doi:10.1038/249810a0, 1974.

Montzka, S., Myers, R., Butler, J., Elkins, J., and Cummings, S.: Global tropospheric distribution and calibration scale of HCFC22, Geophys. Res. Lett., 20, 703-706, doi:10.1029/93GL00753, 1993.

Montzka, S., Butler, J. H., Myers, R. C., Thompson, T. M., Swanson, T. H., Clarke, A. D., Lock, L. T., and Elkins, J. W.: Decline in the tropospheric abundance of halogen from halocarbons: Implications for stratospheric ozone depletion, Science, 272, 13181322, doi:10.1126/science.272.5266.1318, 1996.

Montzka, S., Hall, B., and Elkins, J.: Accelerated increases observed for hydrochlorofluorocarbons since 2004 in the global atmosphere, Geophys. Res. Lett., 36, L03804, doi:10.1029/2008GL036475, 2009.

Murdoch, J. C. and Sandler, T.: The voluntary provision of a pure public good: The case of reduced CFC emissions and the Montreal Protocol, J. Public. Econ., 63, 331-349, doi:10.1016/S00472727(96)01598-8, 1997.

Notholt, J.: FTIR measurements of HF, $\mathrm{N}_{2} \mathrm{O}$ and CFCs during the Arctic polar night with the moon as light source, subsidence during winter 1992/93, Geophys. Res. Lett., 21, 2385-2388, doi:10.1029/94GL02351, 1994.

Rodgers, C. D.: Inverse methods for atmospheric sounding - Theory and practice, edited by: Taylor, F. W., World Scientific, Singapore, 2000.

Rodgers, C. D. and Connor, B. J.: Intercomparison of remote sounding instruments, J. Geophys. Res., 108, 4116, doi:10.1029/2002jd002299, 2003.

Rothman, L. S., Gordon, I. E., Babikov, Y., Barbe, A., Benner, D. C., Bernath, P. F., Birk, M., Bizzocchi, L., Boudon, V., Brown, L. R., Campargue, A., Chance, K., Cohen, E. A., Coudert, L. H., Devi, V. M., Drouin, B. J., Fayt, A., Flaud, J.-M., Gamache, R. R., Harrison, J. J., Hartmann, J.-M., Hill, C., Hodges, J. T., Jacquemart, D., Jolly, A., Lamouroux, J., Roy, R. J. L., Li, G., Long, D. A., Lyulin, O. M., Mackie, C. J., Massie, S. T., Mikhailenk, S., Müller, H. S. P., Naumenko, O. V., and Nikitin, A. V.: The HITRAN2012 molecular spectroscopic database, J. Quant. Spectrosc. Ra., 130, 4-50, doi:10.1016/j.jqsrt.2013.07.002, 2013.

Santer, B. D., Wigley, T., Boyle, J., Gaffen, D. J., Hnilo, J., Nychka, D., Parker, D., and Taylor, K.: Statistical significance of trends and trend differences in layer-average atmospheric temperature time series, J. Geophys. Res.-Atmos., 105, 7337-7356, doi:10.1029/1999JD901105, 2000.

Schneider, M., Hase, F., Blumenstock, T., Redondas, A., and Cuevas, E.: Quality assessment of $\mathrm{O}_{3}$ profiles measured by a state-of-the-art ground-based FTIR observing system, Atmos. Chem. Phys., 8, 5579-5588, doi:10.5194/acp-8-5579-2008, 2008. 
Senten, C., De Mazière, M., Dils, B., Hermans, C., Kruglanski, M., Neefs, E., Scolas, F., Vandaele, A. C., Vanhaelewyn, G., Vigouroux, C., Carleer, M., Coheur, P. F., Fally, S., Barret, B., Baray, J. L., Delmas, R., Leveau, J., Metzger, J. M., Mahieu, E., Boone, C., Walker, K. A., Bernath, P. F., and Strong, K.: Technical Note: New ground-based FTIR measurements at Ile de La Réunion: observations, error analysis, and comparisons with independent data, Atmos. Chem. Phys., 8, 3483-3508, doi:10.5194/acp-8-3483-2008, 2008.

Sherlock, V. J., Jones, N. B., Matthews, W. A., Murcray, F. J., Blatherwick, R. D., Murcray, D. G., Goldman, A., Rinsland, C. P., Bernardo, C., and Griffith, D. W.: Increase in the vertical column abundance of HCFC-22 $\left(\mathrm{CHClF}_{2}\right)$ above Lauder, New Zealand, between 1985 and 1994, J. Geophys. Res.-Atmos., 102, 88618865, doi:10.1029/96JD01012, 1997.

Vigouroux, C., Hendrick, F., Stavrakou, T., Dils, B., De Smedt, I., Hermans, C., Merlaud, A., Scolas, F., Senten, C., Vanhaelewyn, G., Fally, S., Carleer, M., Metzger, J.-M., Müller, J.-F., Van Roozendael, M., and De Mazière, M.: Ground-based FTIR and MAX-DOAS observations of formaldehyde at Réunion Island and comparisons with satellite and model data, Atmos. Chem. Phys., 9, 9523-9544, doi:10.5194/acp-9-9523-2009, 2009.

Vigouroux, C., Stavrakou, T., Whaley, C., Dils, B., Duflot, V., Hermans, C., Kumps, N., Metzger, J.-M., Scolas, F., Vanhaelewyn, G., Müller, J.-F., Jones, D. B. A., Li, Q., and De Mazière, M.: FTIR time-series of biomass burning products $\left(\mathrm{HCN}, \mathrm{C}_{2} \mathrm{H}_{6}\right.$, $\mathrm{C}_{2} \mathrm{H}_{2}, \mathrm{CH}_{3} \mathrm{OH}$, and $\left.\mathrm{HCOOH}\right)$ at Reunion Island $\left(21^{\circ} \mathrm{S}, 55^{\circ} \mathrm{E}\right)$ and comparisons with model data, Atmos. Chem. Phys., 12, 10367-10385, doi:10.5194/acp-12-10367-2012, 2012.

Vigouroux, C., Blumenstock, T., Coffey, M., Errera, Q., García, O., Jones, N. B., Hannigan, J. W., Hase, F., Liley, B., Mahieu, E., Mellqvist, J., Notholt, J., Palm, M., Persson, G., Schneider, M., Servais, C., Smale, D., Thölix, L., and De Mazière, M.: Trends of ozone total columns and vertical distribution from FTIR observations at eight NDACC stations around the globe, Atmos. Chem. Phys., 15, 2915-2933, doi:10.5194/acp-15-2915-2015, 2015. von Clarmann, T., Ceccherini, S., Doicu, A., Dudhia, A., Funke, B., Grabowski, U., Hilgers, S., Jay, V., Linden, A., López-Puertas, M., Martín-Torres, F.-J., Payne, V., Reburn, J., Ridolfi, M., Schreier, F., Schwarz, G., Siddans, R., and Steck, T.: A blind test retrieval experiment for infrared limb emission spectrometry, J. Geophys. Res.-Atmos., 108, 4746, doi:10.1029/2003JD003835, 2003.

Walker, S., Weiss, R., and Salameh, P.: Reconstructed histories of the annual mean atmospheric mole fractions for the halocarbons CFC-11 CFC-12, CFC-113, and carbon tetrachloride, J. Geophys. Res.-Oceans, 105, 14285-14296, doi:10.1029/1999JC900273, 2000.

Zander, R., Mahieu, E., Demoulin, P., Rinsland, C. P., Weisenstein, D. K., Ko, M. K., Sze, N. D., and Gunson, M. R.: Secular evolution of the vertical column abundances of $\mathrm{CHCIF}_{2}$ (HCFC-22) in the Earth's atmosphere inferred from ground-based IR solar observations at the Jungfraujoch and at Kitt Peak, and comparison with model calculations, J. Atmos. Chem., 18, 129-148, doi:10.1007/BF00696811, 1994.

Zander, R., Mahieu, E., Demoulin, P., Duchatelet, P., Servais, C., Roland, G., Delbouille, L., De Mazière, M., and Rinsland, C. P.: Evolution of a dozen non- $\mathrm{CO}_{2}$ greenhouse gases above Central Europe since the mid-1980s, Environ. Sci., 2, 295-303, doi:10.1080/15693430500397152, 2005.

Zander, R., Mahieu, E., Demoulin, P., Duchatelet, P., Roland, G., Servais, C., De Mazière, M., Reimann, S., and Rinsland, C. P.: Our changing atmosphere: Evidence based on long-term infrared solar observations at the Jungfraujoch since 1950, Sci. Total Environ., 391, 184-195, doi:10.1016/j.scitotenv.2007.10.018, 2008. 